\title{
Effects of Oral Calcium Dosage and Timing on Ethanol-Induced Sensitization of Locomotion in DBA/2 Mice
}

\author{
Chikako Shimizu, ${ }^{* a}$ Yutaka Mitani, ${ }^{a}$ Youichi Tsuchiya, ${ }^{a}$ and Toshitaka Nabeshima ${ }^{b, c, d}$ \\ ${ }^{a}$ Frontier Laboratories for Value Creation, SAPPORO HOLDINGS LTD.; 10 Okatome, Yaizu, Shizuoka 425-0013, \\ Japan: ${ }^{b}$ Fujita Health University; 1-98 Dengakugakubo, Kutsukake-cho, Toyoake, Aichi 470-1192, Japan: ${ }^{c}$ Aino \\ University; 4-5-4 Higashi-Ohda, Ibaraki, Osaka 567-0012, Japan: and ${ }^{d}$ NPO Japanese Drug Organization of \\ Appropriate Use and Research; 3-1509 Omoteyama, Tanpaku-ku, Nagoya 468-8503, Japan.
}

Received February 7, 2018; accepted May 3, 2018; advance publication released online May 16, 2018

Ethanol (EtOH) dosage, frequency, and paired associative learning affect the risk of alcoholism. Recently, Spanagel et al. reported that acamprosate calcium (Acam Ca) prescribed for alcoholism exerts an anti-relapse effect via $\mathrm{Ca}$. Ca is contained in foods, sometimes consumed with alcohol. Therefore, we investigated the association among oral $\mathrm{Ca}$ ingestion, EtOH-induced locomotor sensitization, and plasma Ca levels on how to consume Ca for moderate drinking. We used DBA/2 $\mathrm{CrSlc}$ mice, and $\mathrm{CaCl}_{2}$ as water-soluble $\mathrm{Ca}$ salts. For pre-administration, elemental Ca $(50,75,100$, or $150 \mathrm{mg} / \mathrm{kg}$, per os (p.o.)) or water for control was administered $1 \mathrm{~h}$ before EtOH $(2 \mathrm{~g} / \mathrm{kg}, 20 \mathrm{v} / \mathrm{v}(\%) \mathrm{EtOH}$ in saline) administration intraperitoneal (i.p.) for locomotor sensitization or for plasma Ca level changes. For post-administration, elemental Ca (100 mg/kg) was administered $1 \mathrm{~h}$ after EtOH. Moreover, we employed bepridil and the dopamine D1 antagonist, SCH-23390 to further examine the mechanism of EtOH-induced sensitization. The locomotor sensitization segmentalized for $300 \mathrm{~s}$ had two peaks (0-90s and 180-300 s). Pre-administration of Ca (50, 75, and $100 \mathrm{mg} / \mathrm{kg})$ significantly reduced the 0-90-s peak, selectively blocked by SCH-23390, but "non-dose dependently" as Ca $150 \mathrm{mg} / \mathrm{kg} \mathrm{did}$ not have this effect. Bepridil blocked the suppressive effect of pre-administration of Ca $(100 \mathrm{mg} / \mathrm{kg})$. The effective pre-doses of Ca (50-100 mg/kg) maintained plasma Ca basal levels against EtOH-induced decrease of Ca. On the contrary, post-administration of $\mathrm{Ca}$ inversely led to significant promotion of sensitization of both locomotor peaks. Oral Ca intake had diverse effects on EtOH-induced sensitization depending on Ca dosage and timing.

Key words alcoholism; acamprosate calcium; bepridil; ethanol; dopamine antagonist

Heavy and long-term alcohol consumption is associated with an increased risk of more than 200 diseases such as liver cirrhosis, cancer, pancreatitis, depression, and dementia.) Disease burden is related to amount of alcohol consumption and drinking patterns (drinking frequency during the week and in relation to food consumption) ${ }^{1,2)}$ On the contrary, many epidemiological studies have also suggested that moderate alcohol consumption reduces the risk of mortality and of some diseases, such as cardiovascular diseases ${ }^{3,4)}$ and dementia. ${ }^{5}$ Moderate drinking is implicated in health and QOL. For clarifying the influence of moderate alcohol consumption on health, we have reported the risk of reward by moderate-dose/ long-term EtOH administration ${ }^{6)}$ and the relation between moderate/sustained alcohol intake and health during the lifespan in rodents. ${ }^{7)}$

Acamprosate calcium (Acam Ca) is widely used as an anti-relapse medication along with therapy in the treatment of alcohol dependence. ${ }^{8)}$ Acam Ca has an anti-relapse effect and suppresses alcohol reward preclusively following intraperitoneal (i.p.) ${ }^{9)}$ and per os (p.o.) administrations in rodents. ${ }^{6}$ ) The mechanism of action of acamprosate is believed to block glutaminergic $\mathrm{N}$-methyl-D-aspartate receptors and activate gamma-aminobutyric acid type A receptors. ${ }^{10-12)}$ Recently, Spanagel et al. reported that Acam Ca prescribed for alcoholism exerts an anti-relapse effect via $\mathrm{Ca} .{ }^{13)} \mathrm{Ca}$ signaling regulation plays an important role in neuronal cells, although $\mathrm{Ca}$ contribution on the anti-relapse effects of Acam $\mathrm{Ca}$ remains controversial. $^{14,15)}$ Changes in intracellular $\mathrm{Ca}$ dynamics by alcohol stimulation have been observed during the development of alcohol-induced psychological and physical dependence. ${ }^{16,17)}$ The resting concentration of the $\mathrm{Ca}$ ion in the cytoplasm is maintained around $100 \mathrm{~nm}$, reported as 20000 - to 100000 -fold lower than the extracellular concentration. ${ }^{18)}$

On the contrary, plasma $\mathrm{Ca}$ levels are maintained within very narrow limits. ${ }^{19)}$ EtOH intake itself dose-dependently decreases blood $\mathrm{Ca}$ levels, (extracellular concentration for neurons) because of its effects on the parathyroid hormone $(\mathrm{PTH})$, osteocalcin and the excretion of $\mathrm{Ca}$ into urine. ${ }^{20-23)} \mathrm{Ca}$ contribution for $\mathrm{EtOH}$-induced rewarding behaviors seems to be complicated in view of both extracellular and intracellular Ca signaling.

$\mathrm{Ca}$ is contained both in some medicines and in foods, sometimes eaten together with drinking. When we ingest $\mathrm{Ca}$, the concentration of plasma Ca levels is temporarily elevated, while it is decreased by EtOH. We would like to know whether oral $\mathrm{Ca}$ intake would be beneficial for moderate drinking. Therefore, we investigated the relationship among oral Ca dosage and timing on EtOH-induced sensitization as a phenotypic behavior, and the changes in plasma $\mathrm{Ca}$ levels to obtain information on how to consume $\mathrm{Ca}$ for moderate drinking.

We used ethanol-induced sensitization of locomotor activity, a model of neurobehavioral plasticity implicated in addiction that occurs with repeated drug use. ${ }^{24)}$ Many drugs of abuse stimulate locomotor activity and produce sensitization defined as an increase in the reinforcement strength of a drug following repeated exposure. ${ }^{6,25-27)}$ The results of EtOH-induced sensitization were associated with those of the conditioned place preference test in DBA/2. ${ }^{6}$ A significant positive correlation 
was observed between sensitization of dopaminergic neuronal activity and behavioral sensitization induced by ethanol. ${ }^{28)}$

EtOH-induced sensitization is regulated by dopamine D1 receptors. ${ }^{29-31)}$ Further, EtOH-induced behaviors are accompanied by an elevation of intracellular $\mathrm{Ca}{ }^{17,32-34)}$

We previously observed two peaks in locomotor activity for $300 \mathrm{~s}$ induced by EtOH $(2 \mathrm{~g} / \mathrm{kg})$ administration. ${ }^{6)}$ We speculated that both peaks in locomotion are developed in relation to the time-dependent changes in the function of the dopamine D1 receptor by repeated EtOH administration. Therefore, we investigated not only effects of oral $\mathrm{Ca}$ administration on the two peaks of locomotor activity, but also the blockage of the peaks with the dopamine D1 antagonist, SCH-23390.

This study is, to our knowledge, the first report of a relationship among $\mathrm{Ca}$ dosage and timing of administration and plasma $\mathrm{Ca}$ concentration for $\mathrm{EtOH}$-induced sensitization in mice.

\section{MATERIALS AND METHODS}

Subjects We used DBA/2 mice in this study, as DBA/2 mice rapidly express a robust sensitization to EtOH. ${ }^{6,35,36)} \mathrm{Six}$ week-old DBA/2 CrSlc male mice (Japan SLC, Inc., Hamamatsu, Japan) were acclimated to the animal facility for 2 weeks before testing. The animals were group-housed (6 per cage) with ad libitum access to distilled water and standard chow (CRF-1, Charles River Laboratories, Yokohama, Japan). The animal facility was maintained at $23 \pm 1{ }^{\circ} \mathrm{C}$ with $55 \%$ humidity and a 12-h/12-h light/dark cycle.

All experiments were approved by the Institutional Animal Care and Use Committee of SAPPORO BREWERIES LTD. (permit numbers 2015-002, 2016-001, and 2017-001).

Reagents EtOH and $\mathrm{CaCl}_{2} 2$ hydrate were obtained from Wako Pure Chemical Industries, Ltd. (Osaka, Japan) as a special grade chemical. Ca channel blocker, bepridil hydrochloride, and dopamine antagonist, R(+)-SCH-23390 hydrochloride, were obtained from Sigma-Aldrich (St. Louis, MO, U.S.A.). Acam Ca was prepared from Regtect ${ }^{\circledR}$ (Nippon Shinyaku Co., Ltd., Kyoto, Japan) by micronization with a force mill, followed by 3 -time sifting and suspension in distilled water.

Locomotor Sensitization Tests Repeated exposure to alcohol and drugs of abuse enhances the motor-stimulant response termed behavioral sensitization, which has a significant positive correlation with dopaminergic neuronal activity. ${ }^{24-28)}$

For EtOH-induced sensitization, we used a plastic black box $(30 \times 15 \times 15 \mathrm{~cm}$; Brain Science Idea Inc., Osaka, Japan) consisting of two chambers, a black chamber and a white chamber, divided by a sliding door. ${ }^{6}$ Locomotor activity (locomotor distance) in the black area of the chamber was measured using the ANY-maze Video Tracking System (Stoelting Co., Wood Dale, IL, U.S.A.). ${ }^{6}$

Before the sensitization tests, each mouse was placed in the black chamber in all experiments for 300 s once per day for 3 consecutive days as habituation.

Mice received $\mathrm{Ca}$ salts or distilled water by the p.o. route $1 \mathrm{~h}$ before $\mathrm{EtOH}$ administration in consideration of Ca absorption. ${ }^{37)}$ We used $\mathrm{CaCl}_{2}$ as water-soluble $\mathrm{Ca}$ salts. $\mathrm{Ca}$ doses were calculated as elemental $\mathrm{Ca}$ from $\mathrm{CaCl}_{2}$. EtOH $(2.0 \mathrm{~g} / \mathrm{kg})$ was used based on the dose-dependence to induce locomotor sensitization. ${ }^{6}$ EtOH is rapidly absorbed into the blood in a dose-dependent manner, after which it readily crosses the blood-brain barrier and reaches the brain. We, therefore, chose the i.p. route to elucidate the relationship between alcohol dosage and EtOH-induced sensitization.

Locomotor activity was recorded for $300 \mathrm{~s}$ (segmentalized $30 \mathrm{~s})$ after $\mathrm{EtOH}$ or saline administration.

Effects of Ca Dosages before EtOH Administration on EtOH-Induced Sensitization Ca Dosages 50, 100, and $150 \mathrm{mg} / \mathrm{kg}$ (Locomotor Experiment 1)

We investigated whether the $\mathrm{Ca}$ dosage, before $\mathrm{EtOH}$ administration, affected the development of sensitization. Mice $(n=34)$ were assigned to 4 groups (pre-water group: $n=8$, pre-Ca50 group: $n=9$, pre-Ca100 group: $n=8$, and preCa150 group: $n=9$ ). Each mouse received a different dose of $\mathrm{Ca}$ (pre-water group: distilled water, pre-Ca50 group: $\mathrm{Ca}$ $50 \mathrm{mg} / \mathrm{kg}$, pre-Ca100 group: Ca $100 \mathrm{mg} / \mathrm{kg}$, pre-Ca150 group: $\mathrm{Ca} 150 \mathrm{mg} / \mathrm{kg}$, administered by p.o.). One hour later, EtOH $(2 \mathrm{~g} / \mathrm{kg}, 20 \mathrm{v} / \mathrm{v}(\%) \mathrm{EtOH}$ in saline) was administered (i.p.). The sensitization tests were consecutively performed for $5 \mathrm{~d}$ (Admin 1-5, Admin 6-10 and Admin 11-15) with withdrawalintervals of $2 \mathrm{~d}$ (weekends).

Additionally, we examined whether pretreatment with $\mathrm{Ca}$ itself has an effect on locomotor activity (pre-water_saline group and pre-Ca 150_saline group). Mice $(n=8)$ in each group received distilled water or Ca $150 \mathrm{mg} / \mathrm{kg}$ by p.o., respectively. One hour later, saline was administered (i.p.) and we measured locomotor activities (Admin 1-15).

Ca Dosage $75 \mathrm{mg} / \mathrm{kg}$ (Locomotor Experiment 2: Confirmation of Locomotor Experiment 1)

We investigated the effects of $\mathrm{Ca}(75 \mathrm{mg} / \mathrm{kg})$ pre-administration which is the mean between 50 and $100 \mathrm{mg} / \mathrm{kg}$ to confirm the results of experiment 1 . Mice $(n=18)$ were assigned to 2 groups (pre-water group and pre-Ca75 group, each group; $n=9$ ). Each mouse received distilled water (pre-water group, p.o.) or $\mathrm{Ca}(75 \mathrm{mg} / \mathrm{kg}$ ) (pre-Ca75 group, p.o.). One hour later, $\mathrm{EtOH}(2 \mathrm{~g} / \mathrm{kg}, 20 \mathrm{v} / \mathrm{v}(\%) \mathrm{EtOH}$ in saline) was administered (i.p.). The sensitization tests were performed consecutively for $5 \mathrm{~d}$ (Admin 1-5 and Admin 6-10) with a withdrawal-interval of $2 \mathrm{~d}$ (weekend), and consecutively for $4 \mathrm{~d}$ (Admin 11-14 and Admin 15-18) with a withdrawal-interval of $3 \mathrm{~d}$ (weekend plus national holiday).

Antagonism by Ca Channel Blocker (Bepridil) against the Effects of Pre-administration of Ca (Locomotor Experiment 3)

L-Type and $\mathrm{N}$-type $\mathrm{Ca}$ channels are engaged in ethanolinduced behaviors and neurochemical responses. ${ }^{38,39)}$ We investigated whether the $\mathrm{Ca}$ channel blocker prevented the effects of $\mathrm{Ca}$ on EtOH-induced sensitization. We chose a non-selective $\mathrm{Ca}$ channel blocker, bepridil. Mice $(n=25)$ were assigned to three groups (pre-water group: $n=8$, preCa100 group: $n=9$, and pre-Ca100+Bep group, $n=8)$. Each mouse received distilled water (pre-water group, p.o.) or $\mathrm{Ca}$ $100 \mathrm{mg} / \mathrm{kg}$ (pre-Ca100 group, p.o.), or "Ca $(100 \mathrm{mg} / \mathrm{kg}$ ) and bepridil $(50 \mathrm{mg} / \mathrm{kg})$ mixture solution" (pre-Ca100+Bep group, p.o.). One hour later, EtOH ( $2 \mathrm{~g} / \mathrm{kg}, 20 \mathrm{v} / \mathrm{v}(\%) \mathrm{EtOH}$ in saline) was administered (i.p.). The sensitization tests were consecutively performed for $5 \mathrm{~d}$ (Admin 1-5 and Admin 6-10) with a withdrawal-interval of $2 \mathrm{~d}$ (weekend).

Effects of Ca $(100 \mathrm{mg} / \mathrm{kg})$ after EtOH Administration on EtOH-Induced Sensitization (Locomotor Experiment 4)

We investigated whether post-administration of $\mathrm{Ca}$ showed 
similar effects with pre-administration of $\mathrm{Ca}$ on the development of sensitization. Mice $(n=18)$ were assigned to 2 groups (post-water group and post-Ca100 group, each group; $n=9$ ). Each mouse received EtOH $(2 \mathrm{~g} / \mathrm{kg}, 20 \mathrm{v} / \mathrm{v}(\%) \mathrm{EtOH}$ in saline, i.p.) and we recorded locomotor activity for $300 \mathrm{~s}$. One hour after EtOH administration, each mouse received distilled water (post-water group) or $\mathrm{Ca} 100 \mathrm{mg} / \mathrm{kg}$ (post-Ca100 group). The sensitization tests were consecutively performed for $5 \mathrm{~d}$ (Admin 1-5, Admin 6-10, and Admin 11-15) with withdrawal-intervals of $2 \mathrm{~d}$ (weekends).

Inhibition by Dopamine D1 Antagonist of the Development of EtOH-Induced Sensitization (Locomotor Experiment 5)

There were two peaks (0-90s and 180-300s) of locomotor activity during the $300 \mathrm{~s}$ measurement of locomotion induced by EtOH. We investigated whether Ca-effective peak locomotion was concerned with the dopamine D1 receptor.

Mice $(n=36)$ were assigned to 4 groups (saline-saline group, saline-EtOH group, D1-saline group, and D1-EtOH group, each group; $n=9$ ). Mice received saline (saline-saline group and saline-EtOH group, i.p.) or SCH-23390 (0.01 mg/kg) (D1-saline group and D1-EtOH group, i.p.). Thirty minutes later, each group was administered saline (saline-saline group and D1-saline group, i.p.) or EtOH (2 g/kg, $20 \mathrm{v} / \mathrm{v}(\%) \mathrm{EtOH}$ in saline, saline-EtOH group and D1-EtOH group, i.p.). The sensitization tests were consecutively performed for $5 \mathrm{~d}$ (Admin 1-5, Admin 6-10, Admin 11-15, and Admin 16-20) with withdrawal-intervals of $2 \mathrm{~d}$ (weekends).

Measurement of Total Ca Levels in Plasma after the Sensitization Tests Blood was sampled from the tail veins of the mice. After centrifugation at $3000 \mathrm{rpm}$ for $5 \mathrm{~min}$, the Ca concentration was determined by the Ca Assay Kit LS (CA31M, Metallogenics Co., Ltd., Chiba, Japan). We evaluated the relative changes of plasma $\mathrm{Ca}$ levels by $\mathrm{Ca}$ and $\mathrm{EtOH}$ administrations among the same ages after the sensitization tests.

Effects of Acam Ca Administration on Ca Levels in Plasma

We used twelve mice (39 weeks old). The Ca dose in Acam $\mathrm{Ca}(600 \mathrm{mg} / \mathrm{kg})$ corresponded to elemental Ca $(60 \mathrm{mg} / \mathrm{kg})$. Before Acam Ca $(600 \mathrm{mg} / \mathrm{kg})$ administration (p.o.), the first blood was sampled. One hour later, the second blood was sampled for Ca measurement.

Effects of Ca before EtOH Administration on Ca Levels in Plasma

Mice ( $n=36,14$ weeks old) were assigned to 4 groups (water-saline group, water-EtOH group, Ca-saline group and $\mathrm{Ca}-\mathrm{EtOH}$ group, each group; $n=9$ ). Blood was sampled from all mice and just after sampling, $\mathrm{CaCl}_{2}$ solution $(\mathrm{Ca}$ $150 \mathrm{mg} / \mathrm{kg}, \mathrm{Ca}-$ saline group and $\mathrm{Ca}-\mathrm{EtOH}$ group) or distilled water (water-saline group and water-EtOH group) was administered (p.o.). One hour later, saline (water-saline group and $\mathrm{Ca}-$ saline group) or $\mathrm{EtOH}(2 \mathrm{~g} / \mathrm{kg}, 20 \mathrm{v} / \mathrm{v}(\%) \mathrm{EtOH}$ in saline, water-EtOH group and $\mathrm{Ca}-\mathrm{EtOH}$ group) was administered (i.p.) and mice were placed into the sensitization apparatus as was performed for the locomotor activity measurement. Five minutes later, the second blood was sampled.

Dose-Dependent Effects of $\mathrm{Ca}$ before EtOH Administration on Ca Levels in Plasma

Mice ( $n=36,24$ weeks old) were assigned to 4 groups (water group, Ca $50 \mathrm{mg}$ group, $\mathrm{Ca} 100 \mathrm{mg}$ group and $\mathrm{Ca}$
$150 \mathrm{mg}$ group, each group; $n=9$ ). Blood was sampled from all mice and just after sampling, each mouse received a different dose of $\mathrm{Ca}$ (water group: distilled water, Ca50 group: $\mathrm{Ca} 50 \mathrm{mg} / \mathrm{kg}$, Ca100 group: Ca $100 \mathrm{mg} / \mathrm{kg}$, Ca150 group: $\mathrm{Ca}$ $150 \mathrm{mg} / \mathrm{kg}$ ) (p.o.). One hour later, EtOH $(2 \mathrm{~g} / \mathrm{kg}, 20 \mathrm{v} / \mathrm{v}(\%)$ $\mathrm{EtOH}$ in saline) was administered (i.p.) and mice were placed into the sensitization apparatus as was performed for the locomotor activity measurement. Five minutes later, the second blood was sampled.

Effects of Ca after EtOH Administration on Ca Levels in Plasma

Mice ( $n=18,20$ weeks old) were assigned to 2 groups (postwater group and post-Ca100 group, each group; $n=9$ ). Blood was sampled from all mice and just after sampling, each mouse received EtOH $(2 \mathrm{~g} / \mathrm{kg}, 20 \mathrm{v} / \mathrm{v}(\%) \mathrm{EtOH}$ in saline) administration (i.p.) and $1 \mathrm{~h}$ later, received distilled water (postwater group) or $\mathrm{Ca} 100 \mathrm{mg} / \mathrm{kg}$ (post-Ca 100 group) (p.o.). One hour after water or $\mathrm{Ca}$ administration, (approximately $2 \mathrm{~h}$ after the first blood sampling), the second blood was sampled for plasma Ca measurement.

Data Analysis SPSS software 10.0.7 J for Windows (IBM Co., Armonk, NY, U.S.A.) and Microsoft Excel 2013 (Microsoft Corporation, Redmond, WA, U.S.A.) were used for all statistical analyses. Data in the text and figures are presented as mean \pm standard error of the mean (S.E.M.).

\section{Locomotor Sensitization}

Between-group comparisons (Locomotor experiments 1, 2, 3, and 4) were performed by two-way ANOVA followed by Tukey's post-hoc test for multiple comparisons. A three-way ANOVA was applied for Locomotor experiment 5[pretreatment (saline and dopamine D1 antagonist, SCH-23390), treatment (saline or, EtOH), and administration time on locomotor activity], followed by Bonferroni's post-hoc test. Within group comparisons before and after the withdrawal-intervals (between admin 5 and admin 6 , and admin 10 and admin 11 in Locomotor experiment 5 ) were performed by unpaired $t$-test.

\section{Plasma Ca Concentration}

Within-group comparisons for plasma $\mathrm{Ca}$ concentration were performed by paired $t$-test. Between groups comparisons were performed by one-way ANOVA followed by Tukey's post-hoc test.

All data are expressed as means \pm standard error (S.E.) A $p$ value $<0.05$ was considered to be statistically significant.

\section{RESULTS}

\section{Plasma Ca Levels}

\section{Effects of Acam Ca on Plasma Ca Levels}

The average plasma $\mathrm{Ca}$ levels were $2.2 \pm 0.03 \mathrm{~mm}(n=12)$ and $2.4 \pm 0.04 \mathrm{~mm}$ before and $1 \mathrm{~h}$ after Acam Ca $(600 \mathrm{mg} / \mathrm{kg})$ administration, respectively. There was significant change as per the paired $t$-test $(p=0.017)$ before and after Acam Ca $(600 \mathrm{mg} / \mathrm{kg}$, about $60 \mathrm{mg} / \mathrm{kg}$ as elemental $\mathrm{Ca})$ administration.

Effects of Ca before EtOH Administration on Plasma Ca Levels

The results are shown in Fig. 1. There were no significant changes in plasma $\mathrm{Ca}$ levels between the before and after administrations in the water-saline group $(p=0.372)$, but significant changes between the before and after administrations were noted in the $\mathrm{Ca}$-saline group $(p=0.017)$. On the contrary, $\mathrm{EtOH}$ administration significantly reduced plasma $\mathrm{Ca}$ levels 
in the water-EtOH group $(p=0.019)$ but tended to increase plasma Ca levels by pre-administration of $\mathrm{Ca}(150 \mathrm{mg} / \mathrm{kg})$ in the $\mathrm{Ca}-\mathrm{EtOH}$ group $(p=0.100)$.

Dose-Dependent Effects of Ca before EtOH Administration on Plasma Ca Levels

We next examined plasma $\mathrm{Ca}$ levels before $\mathrm{Ca}$ administration and after EtOH administration at three $\mathrm{Ca}$ doses. The dose-dependent changes of plasma $\mathrm{Ca}$ levels are shown in Figs. 2A and 2B. The plasma $\mathrm{Ca}$ concentration was significantly reduced by $\mathrm{EtOH}$ in the water group $(p<0.001)$. On the contrary, by pre-administration of all $\mathrm{Ca}$ doses $(50,100$, and

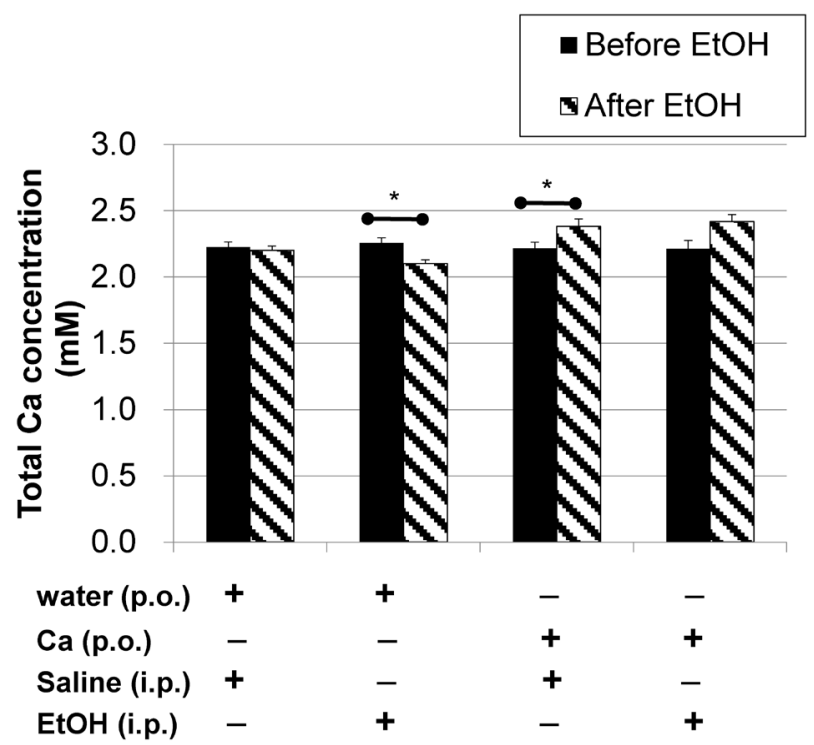

Fig. 1. Effects of $\mathrm{Ca}(150 \mathrm{mg} / \mathrm{kg})$ Administration before EtOH $(2 \mathrm{~g} / \mathrm{kg})$ Administration on Plasma Ca Levels

Mice ( $n=36,14$ weeks old) were assigned to 4 groups (water-saline group, water-EtOH group, $\mathrm{Ca}-$ saline group, and $\mathrm{Ca}-\mathrm{EtOH}$ group, each group; $n=9$ ). Blood was sampled from all mice and just after sampling, Ca $150 \mathrm{mg} / \mathrm{kg}(\mathrm{Ca}-$ saline group and $\mathrm{Ca}-\mathrm{EtOH}$ group) or distilled water (water-saline group and water-EtOH group) was administered (p.o.). One hour later, saline (water-saline group and $\mathrm{Ca}-$ saline group) or EtOH $(2 \mathrm{~g} / \mathrm{kg}, 20 \mathrm{v} / \mathrm{v}(\%) \mathrm{EtOH}$ in saline) (water-EtOH group and $\mathrm{Ca}-\mathrm{EtOH}$ group) was administered (i.p.) and mice were placed into the sensitization apparatus as was performed for the locomotor activity measurement. Five minutes later, the second blood was sampled. *: $p<0.05$, paired $t$-test.

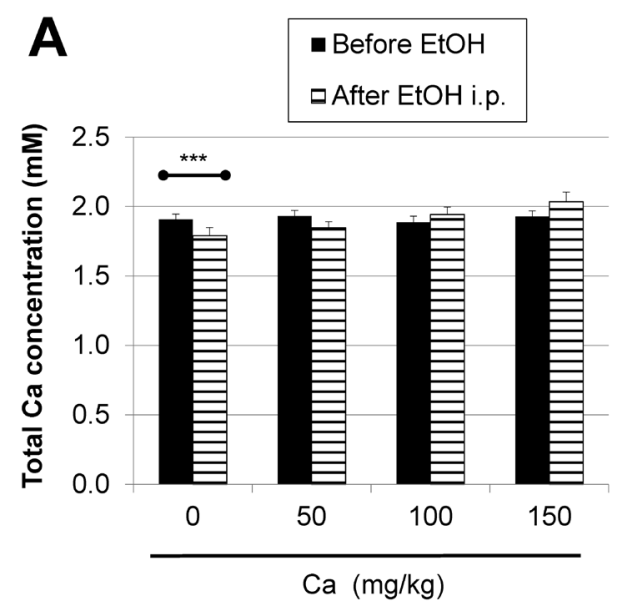

$150 \mathrm{mg} / \mathrm{kg}$ ), there were no significant differences between the before and after administrations $(p=0.649, p=0.474$, and $p=0.114$, respectively) as shown in Fig. $2 \mathrm{~A}$. The changes in plasma $\mathrm{Ca}$ concentration are shown in Fig. 2B. The increase of $\mathrm{Ca}$ in the plasma after $\mathrm{EtOH}$ administration varied dosedependently with the $\mathrm{Ca}$ dosage of pre-administration. The Ca change in the water group was different from that in the Ca150 group $(p=0.061)$. These results suggested that preadministration of $\mathrm{Ca}$ maintains the basal levels of $\mathrm{Ca}$ against EtOH-induced decrease of Ca.

\section{Effects of Ca after EtOH Administration on Plasma Ca} Levels

The changes in plasma $\mathrm{Ca}$ concentration were $-0.08 \pm 0.04$ and $0.04 \pm 0.03 \mathrm{~mm}$ in the post-water and the post-Ca100 groups, respectively. There was no significant difference in the within-group comparison in both groups $(p>0.05)$. The between-group comparison of changes in plasma $\mathrm{Ca}$ was significantly different $(p=0.023)$.

\section{Locomotor Sensitization}

Effects of Ca Dosages before EtOH Administration on EtOH-Induced Sensitization. Ca Dosages 50, 100, and $150 \mathrm{mg} / \mathrm{kg}$, Locomotor Experiment 1

We investigated whether the Ca dosage before EtOH administration affected the development of sensitization. Mice $(n=34)$ were assigned to 4 groups (pre-water group; $n=8$, pre-Ca50 group; $n=9$, pre-Ca100 group; $n=8$, and pre-Ca150 group; $n=9$ ). The locomotor activity for $300 \mathrm{~s}$ (segmentalized $30 \mathrm{~s}$ ) of Admins 1, 5, 10, 12, and 15 in each group is illustrated in Fig. 3A (water group), 3B (pre-Ca50 group), 3C (pre-Ca100 group), and 3D (pre-Ca150 group). With repeated EtOH administrations, the first locomotor peak appeared at $0-90 \mathrm{~s}$ and the second peak at $180-300 \mathrm{~s}$, and both peaks increased with progression of sensitization in the 4 groups, as shown in Figs. $3 \mathrm{~A}-\mathrm{D}$. Most of first locomotion peaks $(0-90 \mathrm{~s})$ were over $4.0 \mathrm{~m}$ in the water and pre-Ca150 groups, but not in the pre-Ca50 and pre-Ca100 groups. The $0-300-\mathrm{s}$ locomotor sensitization is illustrated in Fig. 3E. We performed a two-way ANOVA to assess the effects of $\mathrm{Ca}$ on EtOH-induced locomotor activity. The administration $[F(14,433)=44.3, p<0.001]$ and Ca dosage $[F(3,433)=8.59, p<0.001]$ had significant effects on locomotor

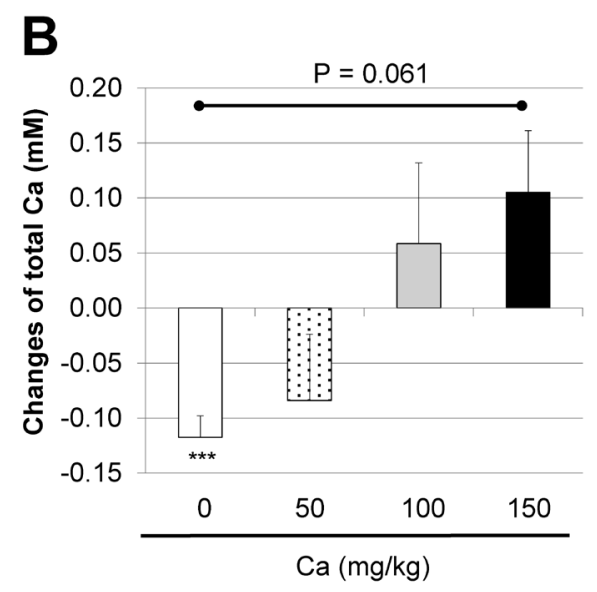

Fig. 2. Pre-administration of Ca Protects EtOH-Induced Decrease in Plasma Ca Levels

Mice ( $n=36,24$ weeks old) were assigned to 4 groups (water group, Ca $50 \mathrm{mg}$ group, Ca $100 \mathrm{mg}$ group, and Ca $150 \mathrm{mg}$ group, each group; $n=9$ ). Blood was sampled from all mice and just after sampling, each mouse received a different dose of Ca (water group: distilled water, $\mathrm{Ca} 50 \mathrm{group}$ : $\mathrm{Ca} 50 \mathrm{mg} / \mathrm{kg}, \mathrm{Ca} 100 \mathrm{group}: \mathrm{Ca} 100 \mathrm{mg} / \mathrm{kg}, \mathrm{Ca} 150$ group: $\mathrm{Ca} 150 \mathrm{mg} / \mathrm{kg})$ (p.o.). One hour later, EtOH ( $2 \mathrm{~g} / \mathrm{kg}, 20 \mathrm{v} / \mathrm{v}(\%)$ EtOH in saline) was administered (i.p.) and mice were placed into the sensitization apparatus as was performed for the locomotor activity measurement. Five minutes later, the second blood was sampled. (A) Plasma Ca levels before and after EtOH administration. $* * *$. $p<0.001$, paired $t$-test. (B) Changes in plasma Ca levels before and after EtOH administration. $p$-value, Tukey's post-hoc test. 

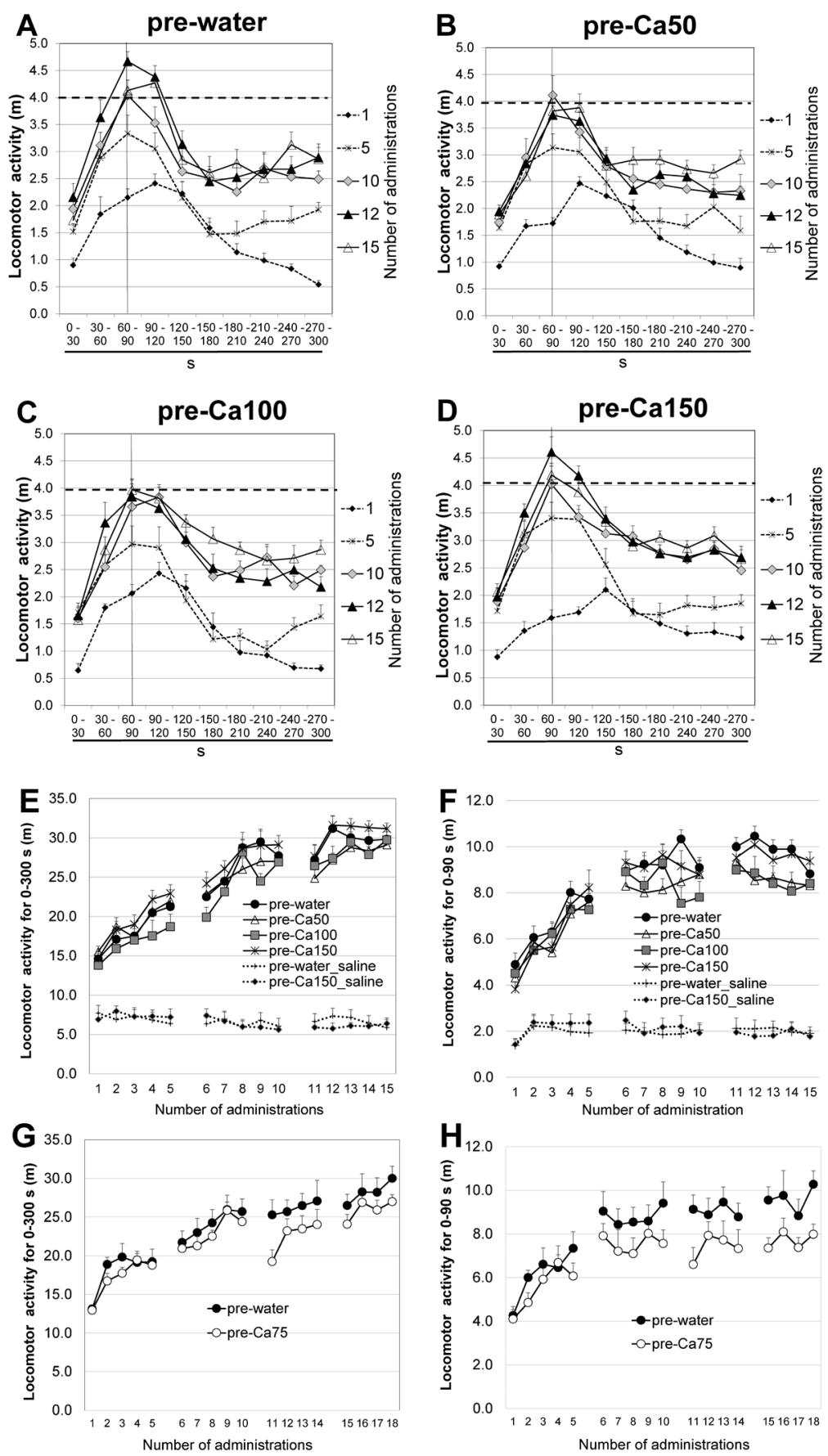

Fig. 3. Effects of Ca Dosage before EtOH Administration on EtOH-Induced Sensitization

Locomotor experiment 1 (Ca dosage (50,100,150 mg/kg) and Locomotor experiment 2 (Ca dosage $75 \mathrm{mg} / \mathrm{kg}$ ). Mice ( $n=34)$ were assigned to 4 groups (pre-water group: $n=8$, pre-Ca50 group: $n=9$, pre-Ca100 group: $n=8$, and pre-Ca150 group: $n=9$ ). Each mouse received a different dose of Ca (pre-water group: water, pre-Ca50 group: Ca $50 \mathrm{mg} / \mathrm{kg}$, pre-Ca100 group: Ca $100 \mathrm{mg} / \mathrm{kg}$, pre-Ca150 group: Ca $150 \mathrm{mg} / \mathrm{kg}$, administered by p.o.). One hour later, EtOH ( $2 \mathrm{~g} / \mathrm{kg}, 20 \mathrm{v} / \mathrm{v}$ (\%) EtOH in saline) was administered (i.p.). The sensitization tests were consecutively performed for $5 \mathrm{~d}$ (Admin 1-5, Admin 6-10, and Admin 11-15) with withdrawal-intervals of $2 \mathrm{~d}$ (weekends). In the pre-water_saline group $(n=8)$ and pre-Ca150_saline group $(n=8)$, mice received distilled water or Ca $150 \mathrm{mg} / \mathrm{kg}$ by p.o.. One hour later, saline was administered (i.p., Admin 1-15). Mice $(n=16)$ were assigned to 2 groups (pre-water_saline group: $n=8$ and pre-Ca150_saline group: $n=8$ ). Mice in each group received distilled water or Ca $150 \mathrm{mg} / \mathrm{kg}$ by p.o., respectively. One hour later, saline was administered (i.p.) and measured locomotor activities (Admin 1-15). A. Locomotor activity for $300 \mathrm{~s}$ (segmentalized $30 \mathrm{~s}$ ) on Admins 1, 5, 10,12, and 15 (Locomotor experiment 1, pre-water group). B. Locomotor activity for $300 \mathrm{~s}$ (segmentalized 30s) on Admins $1,5,10,12$, and 15 (Locomotor experiment 1, pre-Ca50 group). C. Locomotor activity for 300s (segmentalized 30s) on Admins 1, 5, 10, 12, and 15 (Locomotor experiment 1, pre-Ca100 group). D. Locomotor activity for $300 \mathrm{~s}$ (segmentalized $30 \mathrm{~s}$ ) on Admins 1, 5, 10, 12, and 15 (Locomotor experiment 1, pre-Ca150 group). E. Locomotor activity for 0-300 s on Admin 1-15 (Locomotor experiment 1). Solid line; 0 pre-water group, $\triangle$ : pre-Ca50 group, $\square$ : pre-Ca100 group, $*$ : pre-Ca150 group. Broken line; +: pre-water saline group, $\$$ : pre-Ca150 saline group. Pre-water group $v s$. pre-Ca100 group $(p=0.034)$, pre-Ca150 group vs. pre-Ca50 group $(p=0.011)$, and pre-Ca100 group $(p<0.001)$, twoway ANOVA followed by Tukey's post-hoc test. F. Locomotor activity for 0-90s on Admin 1-15 (Locomotor experiment 1). Solid line; $\bullet$ : pre-water group, $\triangle$ : pre-Ca50 group, $\square$ : pre-Ca100 group, $*$ : pre-Ca150 group. Broken line; +: pre-water_saline group, $\bullet$ : pre-Ca150_saline group. Pre-water group vs. pre-Ca50 group $(p=0.001)$, pre-Ca100 group $(p=0.003)$ and pre-Ca150 group $(p=0.833)$, pre-Ca150 group $v s$. pre-Ca50 group $(p=0.014)$ and pre-Ca100 group $(p=0.033)$, two-way ANOVA followed by Tukey's post-hoc test. G. Locomotor activity for $0-300 \mathrm{~s}$ on Admin 1-18 (Locomotor experiment 2). Mice $(n=18)$ were assigned to 2 groups (pre-water group and preCa75 group, each group; $n=9$ ). Each mouse received distilled water (pre-water group, p.o.) or Ca $(75 \mathrm{mg} / \mathrm{kg}$ ) (pre-Ca75 group, p.o.). One hour later, EtOH ( $2 \mathrm{~g} / \mathrm{kg}, 20 \mathrm{v} / \mathrm{v}$ (\%) EtOH in saline) was administered (i.p.). The sensitization tests were performed consecutively for $5 \mathrm{~d}$ (Admin 1-5 and Admin 6-10) with a withdrawal-interval of $2 \mathrm{~d}$ (weekend), and consecutively for 4d (Admin 11-14 and Admin 15-18), with a withdrawal-interval of 3d. @: pre-water group, O: pre-Ca75 group. Group ( $p<0.001)$, administration $(p<0.001)$ and group $v s$. administration $(p=0.972)$, two-way ANOVA. H. Locomotor activity for $0-90$ s on Admin 1-18 (Locomotor experiment 2). $\bullet:$ pre-water group, O: pre-Ca75 group. Group $(p<0.001)$, administration $(p<0.001)$ and group $v s$. administration $(p=0.961)$, two-way ANOVA. Pre: pre-administration. 
activity, but there was no interaction between the administration and Ca dosage $[F(42,433)=0.42, p=1.000]$. Using Tukey's post-hoc test to perform between-group comparisons, there was a significant difference between the water group and the pre-Ca100 group $(p=0.034)$. Moreover, the pre-Ca150 group differed significantly from the pre-Ca50 group $(p=0.011)$ and the pre-Ca100 group $(p<0.001)$, but not the pre-water group $(p=0.253)$. The results of the $0-90$-s locomotor sensitization are shown in Fig. 3F. The administration $[F(14,433)=28.1$, $p<0.001]$ and Ca dosage $[F(3,433)=7.82, p<0.001]$ had significant effects on locomotor activity, but there was no interaction between the administration and Ca dosage $[F(42$, $433)=0.65, p=0.957]$. Using Tukey's post-hoc test, the prewater group differed significantly from both the pre-Ca50 group ( $p=0.001)$ and the pre-Ca100 group $(p=0.003)$, but not from the pre-Ca150 group $(p=0.833)$. The pre-Ca150 group was also significantly different from the pre-Ca50 group $(p=0.014)$ and the pre-Ca100 group $(p=0.033)$.

Thus, the Ca pre-dosage effect was not dose-dependent.

Oral water or $\mathrm{Ca} 150 \mathrm{mg} / \mathrm{kg}$ administration itself did not have an effect on locomotor activity (pre-water_saline group and pre-Ca150_saline group, Figs. 3E and 3F).

\section{Ca Dosage $\overline{\mathbf{7}} \mathbf{5} \mathbf{~ m g} / \mathbf{k g}$ (Locomotor Experiment 2)}

As shown in Fig. 2B, the plasma Ca levels after EtOH administration did not change by pre-administration of $\mathrm{Ca}$ $(50-100 \mathrm{mg} / \mathrm{kg})$. We confirmed the effect of Ca on sensitization using $\mathrm{Ca}(75 \mathrm{mg} / \mathrm{kg})$ as the mean dose between 50 and $100 \mathrm{mg} / \mathrm{kg}$.

The 0-300-s locomotor sensitization and 0-90-s locomotor sensitization induced by EtOH are illustrated in Figs. 3G and $3 \mathrm{H}$. Using a two-way ANOVA to assess the effects of groups and administrations (Admin 1-18) on EtOH-induced locomotor activity, the administration $[F(17,281)=13.3, p<0.001]$ and group $[F(1,281)=13.0, p<0.001]$ had significant effects on locomotor activity. However, there was no interaction between administration and group $[F(17,281)=0.45, p=0.972]$ in the 0-300-s locomotor sensitization (Fig. 3G). Moreover, in the $0-90$-s locomotor sensitization, the administration $[F(17$, $281)=6.45, p<0.001]$ and group $[F(1,281)=28.3, p<0.001]$ had significant effects on locomotor activity, but there was no interaction between administration and group $[F(17,281)=0.48$, $p=0.961]$ (Fig. 3H).

Antagonism by Ca Channel Blocker (bepridil) against the Effects of Pre-administration of $\mathrm{Ca}$ (Locomotor Experiment 3)

We investigated whether the Ca channel blocker prevented the effects of $\mathrm{Ca}$ on sensitization of locomotion induced by EtOH. Mice $(n=25)$ were assigned to three groups (pre-water group: $n=8$, pre-Ca100 group: $n=9$, and pre-Ca100+Bep group: $n=8$ ). The $0-300$-s locomotor sensitization and $0-90-\mathrm{s}$ locomotor sensitization are illustrated in Figs. 4A and 4B, respectively. We conducted a two-way ANOVA to assess the effects of the 3 groups and administrations (Admin 1-10) on EtOH-induced locomotor activity. In the 0-300-s locomotor sensitization (Fig. 4A), the administration $[F(9,216)=20.2$, $p<0.001]$ had significant effects on locomotor activity, but there was no significant difference in group $[F(2,216)=0.322$, $p=0.725]$ and no interaction between the administration and group $[F(18,216)=0.321, p=0.997]$. In the $0-90$-s locomotor sensitization (Fig. 4B), the administration $[F(9,216)=32.2$, $p<0.001]$ and group $[F(2,216)=8.11, p<0.001]$ had significant effects on locomotor activity, but there was no interaction between the administration and group $[F(18,216)=0.279$, $p=0.999]$. Using Tukey's post-hoc test, the pre-water group differed significantly from the pre-Ca100 group $(p=0.004)$, but not the pre-Ca100+Bep group $(p=0.842)$. Moreover, the pre-Ca100 group differed significantly from the preCa100+Bep group $(p<0.001)$. Pre-administration of bepridil significantly blocked the suppression effects of $\mathrm{Ca}(100 \mathrm{mg} / \mathrm{kg})$ on 0-90-s locomotor sensitization, but not that of 0-300 s.

Effects of Ca $(100 \mathrm{mg} / \mathrm{kg})$ after EtOH Administration on EtOH-Induced Sensitization (Locomotor Experiment 4)

We investigated whether $\mathrm{Ca}$ after $\mathrm{EtOH}$ administration showed similar effects as the pre-administration of $\mathrm{Ca}$ on EtOH-induced sensitization of locomotion. Mice $(n=18)$ were assigned to 2 groups (post-water group and post-Ca100 group, each group; $n=9$ ). The locomotor activity for $300 \mathrm{~s}$ (segmentalized $30 \mathrm{~s}$ ) of Admins 1, 5, 10, 12, and 15 in each group is
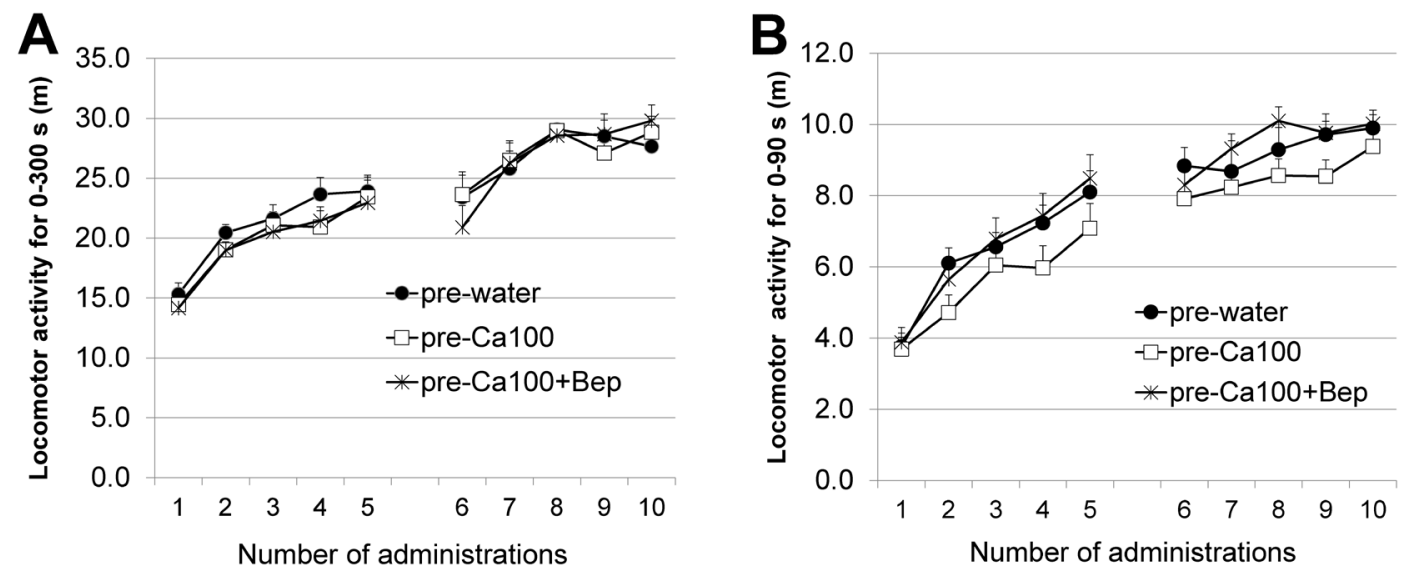

Fig. 4. Antagonism by Ca Channel Blocker (Bepridil) against the Effects of Pre-administration of Ca (Locomotor Experiment 3)

Mice $(n=25)$ were assigned to 3 groups (pre-water group: $n=8$, pre-Ca100 group: $n=9$, and pre-Ca100+Bep group, $n=8$ ). Each mouse received distilled water (pre-water group, p.o.) or Ca $100 \mathrm{mg} / \mathrm{kg}$ (pre-Ca100 group, p.o.), or "Ca $(100 \mathrm{mg} / \mathrm{kg})$ and bepridil $(50 \mathrm{mg} / \mathrm{kg}) \mathrm{mixture}$ solution" (pre-Ca100+Bep group, p.o.). One hour later, EtOH $(2 \mathrm{~g} / \mathrm{kg}, 20 \mathrm{v} / \mathrm{v}(\%)$ EtOH in saline) was administered (i.p.). The sensitization tests were consecutively performed for days (Admin 1-5, and Admin 6-10) with a withdrawalinterval of $2 \mathrm{~d}$ (weekend). (A) Locomotor activity for $0-300 \mathrm{~s}$ on Admin 1-10. ๑: pre-water group, $\square$ : pre-Ca100 group, *: pre-Ca100+Bep group. Group ( $p=0.725$ ), administration $(p<0.001)$ and group $v s$. administration $(p=0.997)$, two-way ANOVA. (B) Locomotor activity for $0-90$ s on Admin 1-10. 0 : pre-water group, $\square$ : pre-Ca100 group, *: pre-Ca100+Bep group. Pre-water group vs. pre-Ca100 group $(p=0.004)$ and pre-Ca100+Bep group $(p=0.842)$, pre-Ca100 group vs. pre-Ca100+Bep group $(p<0.001)$, two-way ANOVA followed by Tukey's post-hoc test. Pre: pre-administration. Bep: bepridil. 
illustrated in Fig. 5A (post-water group) and 5B (post-Ca100 group). Most of the first locomotion peaks (0-90s) were about $4.0 \mathrm{~m}$ in the water group in this experiment (Fig. 5A), but about $5.0 \mathrm{~m}$ in the post-Ca100 group (Fig. 5B).

Using a two-way ANOVA to assess the effects of groups and administrations (Admin 1-15) on EtOH-induced 300-s locomotor activity, the administration $[F(14,235)=24.4$, $p<0.001]$ and group $[F(1,235)=30.4, p<0.001]$ had significant effects on locomotor activity. However, there was no interaction between administration and group $[F(14,235)=1.64$, $p=0.069$ ] in the $0-300$-s locomotor sensitization. The $0-90$-s locomotor sensitization and 180-300-s locomotor sensitization are illustrated in Figs. 5C and 5D. In the 0-90-s locomotor sensitization (Fig. 5C), the administration $[F(14,235)=10.6$, $p<0.001]$ and group $[F(1,235)=14.7, p<0.001]$ had significant effects on locomotor activity, but there was no interaction between administration and group $[F(14,235)=1.37, p=0.170]$. In the 180-300-s locomotor sensitization (Fig. 5D), the administration $[F(14,235)=26.6, p<0.001]$ and group $[F(1,235)=23.5$, $p<0.001$ ] had significant effects on locomotor activity, but there was no interaction between administration and group
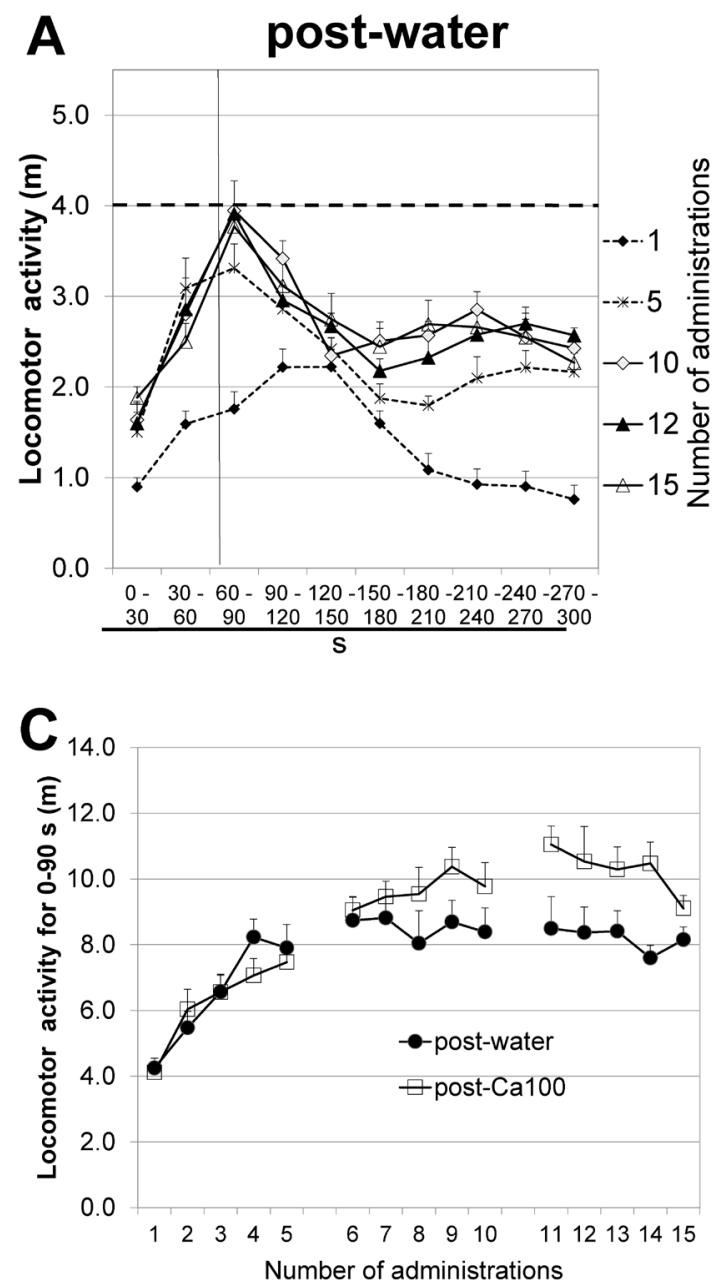

$[F(14,235)=0.801, p=0.667]$. Moreover, the $180-300-\mathrm{s}$ locomotor activity in the post-Ca100 group was significantly reduced at the withdrawal-interval (admin $5 \mathrm{vs}$. admin 6, $p=0.035$, and admin $10 v s$. admin $11, p=0.036$ ) by unpaired $t$-test within the post-Ca100 group, but not in the post-water group $(p>0.05)$.

The Ca $(100 \mathrm{mg} / \mathrm{kg})$ after EtOH administration significantly promoted both the $0-90 \mathrm{~s}$ and $180-300 \mathrm{~s}$ peaks of the EtOHinduced sensitization.

Inhibition by Dopamine D1 Antagonist of the Development of EtOH-Induced Sensitization (Locomotor Experiment 5)

The dopamine D1 receptor signaling system regulates ryanodine receptors, a group of $\mathrm{Ca}$ channels, which play a role in expression in EtOH dependence. ${ }^{33)}$ Activation of inositol 1,4,5-trisphosphate (IP3)-induced $\mathrm{Ca}^{2+}$ signaling by dopamine is mediated thorough D1 dopamine receptors. ${ }^{34)}$ We investigated whether the Ca-effective 0-90-s and 180-300-s locomotor activities were concerned with the dopamine D1 receptor.

Mice $(n=36)$ were assigned to 4 groups (saline-saline group, saline-EtOH group, D1-saline group, and D1-EtOH
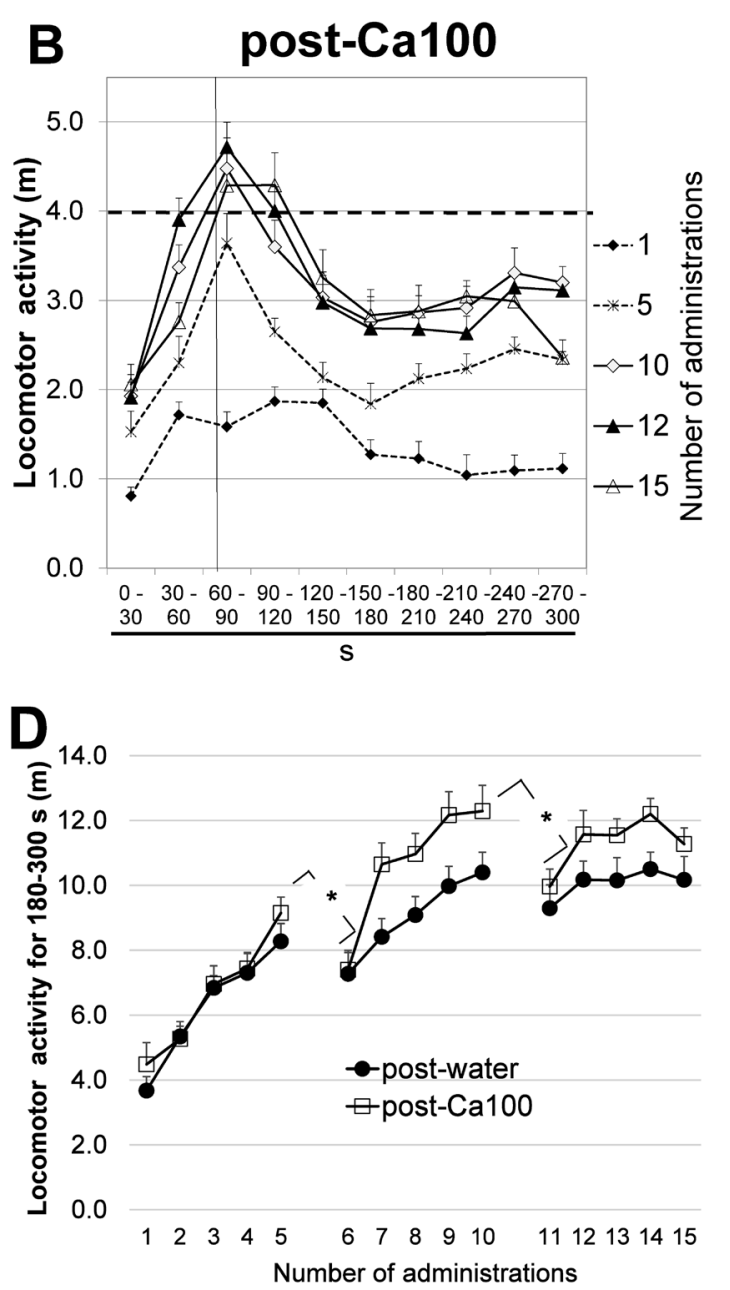

Fig. 5. Effects of $\mathrm{Ca}$ after EtOH Administration on the EtOH-Induced Sensitization (Locomotor Experiment 4)

Mice $(n=18)$ were assigned to 2 groups (post-water group and post-Ca100 group, each group; $n=9)$. Each mouse received EtOH (2 g/kg, $20 \mathrm{v} / \mathrm{v}(\%)$ EtOH in saline) (i.p.) and we recorded locomotor activity for $300 \mathrm{~s}$. One hour after EtOH administration, each mouse received distilled water (post-water group) or Ca $100 \mathrm{mg} / \mathrm{kg}$ (post-Ca100 group). The sensitization tests were consecutively performed for $5 \mathrm{~d}$ (Admin 1-5, Admin 6-10, and Admin 11-15) with withdrawal-intervals of 2d (weekends). (A) Locomotor activity for $300 \mathrm{~s}$ (segmentalized $30 \mathrm{~s}$ ) on Admins 1, 5, 10, 12 and 15 (post-water group). (B) Locomotor activity for $300 \mathrm{~s}$ (segmentalized $30 \mathrm{~s}$ ) on Admins $1,5,10$ 12 and 15 (post-Ca100 group). (C) Locomotor activity for $0-90$ s on Admin 1-15. $\bullet$ : post-water group, $\square$ : post-Ca100 group. Group ( $p<0.001$ ), administration ( $p<0.001)$ and group $v s$. administration ( $p=0.069$ ), two-way ANOVA. (D) Locomotor activity for $180-300$ s on Admin 1-15. @: post-water group: $\square$ : post-Ca100 group. Group $(p<0.001)$, administration $(p<0.001)$ and group $v s$. administration $(p=0.170)$, two-way ANOVA. Within group comparison before and after withdrawal-interval (admin 5 $v s$. admin 6, and admin $10 v s$. admin 11), *: $p<0.05$ by unpaired $t$-test. Post: post-administration. 


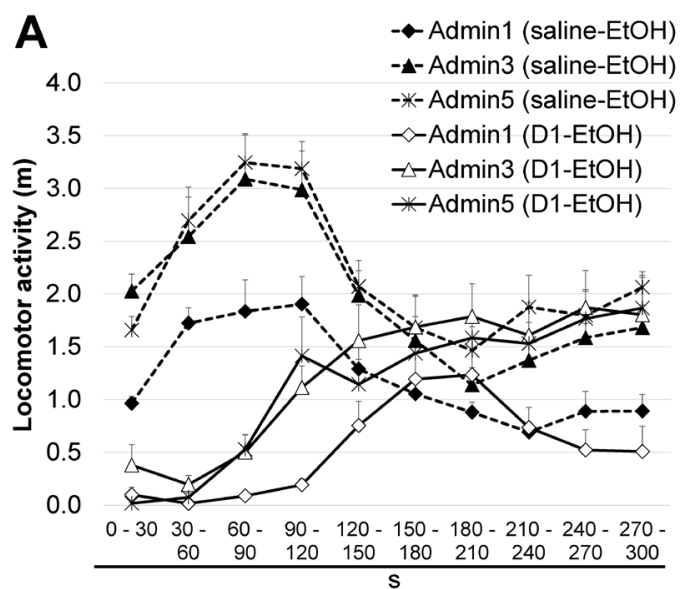

B

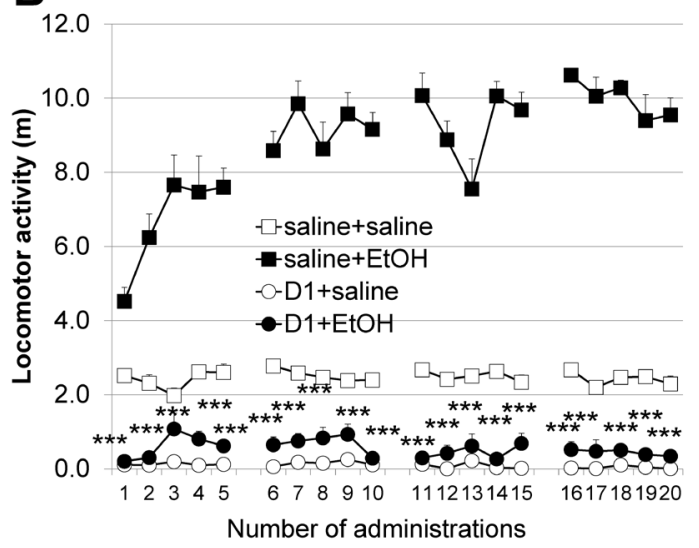

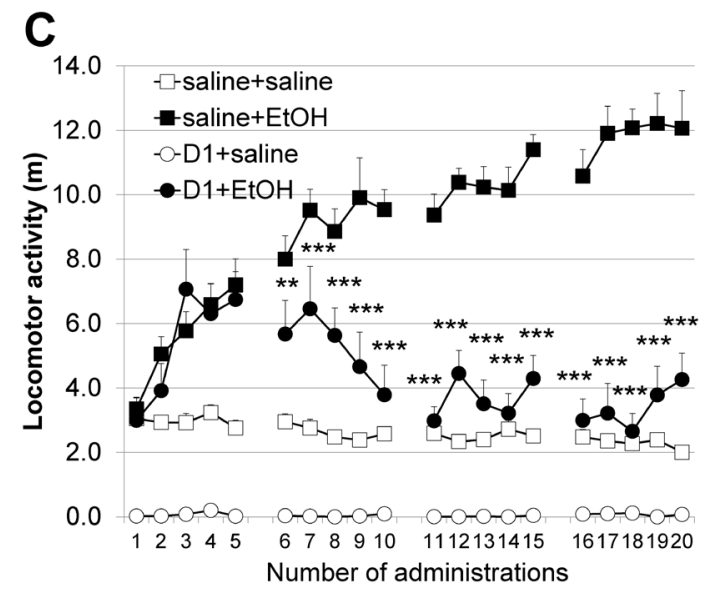

Fig. 6. Inhibition by Dopamine D1 Antagonist of the Development of EtOH-Induced Sensitization (Locomotor Experiment 5)

Mice $(n=36)$ were assigned to 4 groups (saline-saline group, saline-EtOH group, D1-saline group, and D1-EtOH group, each group; $n=9)$. Mice received saline (saline-saline group and saline-EtOH group, i.p.) or SCH-23390 $(0.01 \mathrm{mg} / \mathrm{kg})$ (D1-saline group and D1-EtOH group, i.p.). Thirty minutes later, each group was administered saline (saline-saline group and D1-saline group, i.p.) or EtOH $(2 \mathrm{~g} / \mathrm{kg}, 20 \mathrm{v} / \mathrm{v}(\%) \mathrm{EtOH}$ in saline) (saline-EtOH group and D1-EtOH group, i.p.). The sensitization tests were consecutively performed for $5 \mathrm{~d}$ (Admin 1-5, Admin 6-10, Admin 11-15, and Admin 16-20) with withdrawal-intervals of $2 \mathrm{~d}$ (weekends). (A) Locomotor activity for $300 \mathrm{~s}$ (segmentalized $30 \mathrm{~s}$ ) on Admins 1, 3, and 5 (saline-EtOH group and D1-EtOH group). (B) Locomotor activity for 0-90s on Admin 1-Admin 20. $\square$ : saline-saline group, —: saline-EtOH group, O: D1-saline group, @: D1-EtOH group. Saline-EtOH group vs. D1-EtOH group, ***: $p<0.001$, three-way ANOVA followed by Bonferroni's post-hoc test. (C) Locomotor activity for 180-300s on Admin 1-20. $\square$ : saline-saline group, 口: saline-EtOH group, O: D1-saline group, $\mathbf{0}$ : D1-EtOH group. Saline-EtOH group vs. D1-EtOH group, ${ }^{* *}: p<0.01,{ }^{* * *}: p<0.001$, three-way ANOVA followed by Bonferroni's post-hoc test. Admin: administration. D1: D1 antagonist (SCH-23390). EtOH: ethanol.

group, each group; pretreatment-treatment, $n=9)$. The locomotor activity for $300 \mathrm{~s}$ (segmentalized 30s) of Admins 1, 3 , and 5 in the saline-EtOH group and D1-EtOH group is illustrated in Fig. 6A. From Admin 1-5, the first locomotor peak (0-90s) was blocked by SCH-23390 $(0.01 \mathrm{mg} / \mathrm{kg})$, but not the second locomotor peak (180-300s). The $0-90-\mathrm{s}$ and 180-300-s locomotor sensitizations are illustrated in Figs. 6B and $6 \mathrm{C}$.

In the locomotor activities (0-90s) (Fig. 6B), a three-way ANOVA to assess the influence of pretreatment (saline and $\mathrm{SCH}-23390$ ), treatment (saline and EtOH), and administration time on locomotor activity demonstrated significant main effects of pretreatment $[F(1,622)=4601.3 ; p<0.001]$, treatment $[F(1,622)=1872.8 ; p<0.001]$, and administration time $[F(19,622)=5.17 ; p<0.001]$, as well as significant interactions between pretreatment and treatment $[F(1,622)=1406.6$; $p<0.001]$, and pretreatment and administration time $[F(19$, $622)=5.37 ; p<0.001]$, treatment and administration time $[F(19$, $622)=5.17 ; p<0.001]$, and pretreatment, treatment and administration time $[F(19,622)=4.69 ; p<0.001]$. Using Bonferroni's post-hoc test, the locomotor activity in the D1-saline group was significantly lower than that in the saline-saline group $(p<0.001$; Admin 1-20) at SCH-23390 (0.01 mg/kg). The locomotor activity in the D1-EtOH group was significantly lower than that in the saline-EtOH group $(p<0.001$; Admin $1-20)$, although a great deal of thought should be given to the dose of SCH-23390 used (Fig. 5B). The SCH-23390 (0.01 mg/kg) predose blocked EtOH-induced locomotion (0-90s).

In the locomotor activities (180-300s) (Fig. 6C), a threeway ANOVA to assess the influence of pretreatment (saline and SCH-23390), treatment (saline and EtOH), and administration time on locomotor activity demonstrated significant main effects of pretreatment $[F(1,622)=691.8 ; p<0.001]$, treatment $[F(1,622)=1550.3 ; p<0.001]$, and administration time $[F(19,622)=3.16 ; p<0.001]$, as well as significant interactions between pretreatment and treatment $[F(1,622)=63.4$; $p<0.001]$, and pretreatment and administration time $[F(19$, $622)=5.98 ; p<0.001]$, treatment and administration time $[F(19$, $622)=4.33 ; p<0.001]$, and pretreatment, treatment and administration time $[F(19,622)=8.10 ; p<0.001]$.

Using Bonferroni's post-hoc test, the locomotor activity in the D1-saline group was significantly lower than that in the saline-saline group $(p<0.05$; Admin $1-20)$. On the contrary, the locomotor activity from Admin 1 to Admin 5 in the D1-EtOH 
group did not significantly differ from that in the salineEtOH group ( $p>0.05$, Fig. 6C) unlike the 0-90-s locomotion $(p<0.001$, Fig. 6B). From Admin 6-20, there was a significant difference between the saline-EtOH group and the D1-EtOH group ( $p=0.008 ;$ Admin 6, $p<0.001 ;$ Admin 7-20). The $\mathrm{SCH}-23390(0.01 \mathrm{mg} / \mathrm{kg})$ pre-dose did not block EtOH-induced locomotion in the early stage of sensitization (like Admin 1-5), but blocked it after the progression of sensitization.

\section{DISCUSSION}

Changes in Plasma Ca Levels by Ca (p.o.) and/or EtOH (i.p.) In our previous study, Acam Ca $(600 \mathrm{mg} / \mathrm{kg}$; p.o. $) 1 \mathrm{~h}$ before EtOH-conditioning significantly reduced the development of EtOH-induced CPP. ${ }^{\text {) }}$ The molecular weight (MW) of elemental $\mathrm{Ca}$ per Acam $\mathrm{Ca}$ is about 1/10 (Ca: MW 40, Acam Ca: MW 400.48). At this dose, plasma Ca levels were significantly increased $1 \mathrm{~h}$ post administration. In other studies, using rodents, the doses of Acam $\mathrm{Ca}$ that significantly suppressed CPP or sensitization induced by EtOH $2 \mathrm{~g} / \mathrm{kg}$ (i.p.) were $300 \mathrm{mg} / \mathrm{kg}$ (p.o.), ${ }^{40)} 400 \mathrm{mg} / \mathrm{kg}$ (i.p.), ${ }^{41)}$ and $300 \mathrm{mg} / \mathrm{kg}$ (i.p.). ${ }^{9)}$ Since plasma $\mathrm{Ca}$ levels after $\mathrm{Ca}$ salt administration were rapidly increased by i.p. compared to p.o. administration, ${ }^{37)}$ the Acam $\mathrm{Ca}$ dose in those reports may be sufficient for temporal changes in plasma $\mathrm{Ca}$ levels.

Next, we used $\mathrm{CaCl}_{2}$ as water-soluble $\mathrm{Ca}$ salts. Although $\mathrm{Ca}$ is absorbed in the mammalian small intestine, there might be a difference in $\mathrm{Ca}$ absorption rate between Acam $\mathrm{Ca}$ and Ca salts with food additives. ${ }^{42-44)}$ Therefore, we first examined plasma Ca changes with a high dose of $\mathrm{Ca}(150 \mathrm{mg} / \mathrm{kg})$. As shown in Fig. 1, plasma Ca levels significantly decreased by $\mathrm{EtOH}(2 \mathrm{~g} / \mathrm{kg}$, i.p.) administration as previously reported. $^{22,23,45)}$ Plasma Ca levels were significantly increased $1 \mathrm{~h}$ after pre-administration of $\mathrm{Ca}(150 \mathrm{mg} / \mathrm{kg})$, a period nearly equivalent to that required for maximum plasma $\mathrm{Ca}$ levels after oral $\mathrm{Ca}$ administration. Moreover, the pre-administration of $\mathrm{Ca}(150 \mathrm{mg} / \mathrm{kg})$ prevented the decrease of plasma Ca by EtOH and kept the baseline plasma Ca levels.

As shown in Fig. 2A, pre-administration of $\mathrm{Ca}$ $(50-150 \mathrm{mg} / \mathrm{kg})$ prevented the decrease of plasma Ca levels induced by EtOH. The Ca levels in the plasma of EtOH groups were dose-dependently increased by pre-administration of $\mathrm{Ca}$ (Fig. 2B), even though plasma Ca levels are strictly controlled within very narrow limits. ${ }^{18,19)}$ The pre-administration doses of $\mathrm{Ca}$ to maintain the baseline of plasma $\mathrm{Ca}$ levels after $\mathrm{EtOH}$ $2 \mathrm{~g} / \mathrm{kg}$ (i.p.) were between 50 and $100 \mathrm{mg} / \mathrm{kg}$. From these results, the decrease of plasma $\mathrm{Ca}$ by EtOH could be prevented by pre-administration of $\mathrm{Ca}$ salts.

Next, we investigated whether Ca dosages $(50-150 \mathrm{mg} / \mathrm{kg})$ before $\mathrm{EtOH}(2 \mathrm{~g} / \mathrm{kg})$ administration blocked the development of sensitization.

\section{Locomotor Sensitization}

Inhibitory Effects of Ca Dosages before EtOH
Administration on
(Locomotor Experiments 1 and 2)

Locomotor sensitization had a significant positive correlation with dopaminergic neuronal activity. ${ }^{28)}$ The measurement of locomotor activity after drug use such as cocaine and methamphetamine is normally examined for a certain period of time (e.g., $5 \mathrm{~min}-2 \mathrm{~h}$ varied with tests); however, segmentalized changes in locomotor activity like in $30 \mathrm{~s}$ intervals have not been reported. In our previous study, ${ }^{6}$ we found two elevated peaks of locomotor activity during a 300-s measurement after repeated $\mathrm{EtOH}$ administrations. In this experiment, we found reproducible results that locomotor activity during the 300 -s measurement had two peaks at $0-90 \mathrm{~s}$ and $180-300 \mathrm{~s}$. With the progression of EtOH-induced sensitization, both locomotor peaks became larger, as shown in Figs. 3A-3D. The $0-90$-s locomotor activity in the pre-Ca50 and pre-Ca100 groups were under $4.0 \mathrm{~m}$ of locomotor activity and lower than in the pre-water and pre-Ca150 groups.

There were no significant differences of both $0-300-\mathrm{s}$ and $0-90$-s locomotor activities between the pre-water and pre-Ca150 groups, as shown in Figs. 3E and 3F. On the contrary, the pre-administration of $\mathrm{Ca}(100 \mathrm{mg} / \mathrm{kg})$ significantly reduced both $0-300-\mathrm{s}$ and $0-90$-s locomotor activity (Figs. 3E, 3F). Further, the sensitization of the first peak of $0-90 \mathrm{~s}$, not the second peak of 180-300 s, was suppressed by pre-administration of $\mathrm{Ca}(50 \mathrm{mg} / \mathrm{kg}$ and $\mathrm{Ca} 100 \mathrm{mg} / \mathrm{kg}$, Figs. $3 \mathrm{~A}-3 \mathrm{D}$ and $3 \mathrm{~F}$ ). Moreover, the sensitization of the pre-Ca150 group was significantly different from that of the pre-Ca50 and pre-Ca100 groups (Fig. 3F). The suppressed effects of $\mathrm{Ca}$ on locomotor sensitization was not dose-depended. The effective $\mathrm{Ca}$ doses corresponded to pre-administration doses of $\mathrm{Ca} 50-100 \mathrm{mg} / \mathrm{kg}$, which prevented the decrease of plasma $\mathrm{Ca}$ levels by EtOH ( $2 \mathrm{~g} / \mathrm{kg})$ (Fig. 2B).

Additionally, we conducted pre-administration of $\mathrm{Ca}$ at the dose of $\mathrm{Ca}(75 \mathrm{mg} / \mathrm{kg})$, as the mean between $50-100 \mathrm{mg} / \mathrm{kg}$ (Locomotor experiment 2) to confirm the hypothesis on the role of $\mathrm{Ca}$ on $\mathrm{EtOH}$-induced sensitization. As shown in Figs. $3 \mathrm{G}$ and $3 \mathrm{H}$, with pre-administration of $\mathrm{Ca}(75 \mathrm{mg} / \mathrm{kg})$, the EtOH-induced sensitization was significantly reduced compared to that in the pre-water group in both the 0-300-s and $0-90$-s locomotor sensitizations. These results confirmed those of Locomotor experiment 1. Moreover, the pre-administration of $\mathrm{Ca}$ was effective after the progression of sensitization (e.g., since Admin 11) compared to the process of sensitization formation (e.g., Admin 1-5). We believe that the optimal $\mathrm{Ca}$ dose against constant $\mathrm{EtOH}$ administration differs depending on the stage of sensitization progression and may be higher after the progression of sensitization.

\section{Antagonism by Ca Channel Blocker (Bepridil) against Effects of Pre-administration of Ca (Locomotor Experiment 3)}

To examine the effects of pre-Ca administration, we used the non-selective $\mathrm{Ca}$ channel blocker, bepridil $(50 \mathrm{mg} / \mathrm{kg})$. Bepridil hydrochloride is insoluble in water. Dimethyl sulfoxide is often used to make it soluble, but we were concerned about its toxicity in repeated administration (i.p.). To avoid the toxicity of dimethyl sulfoxide, bepridil was suspended in $\mathrm{CaCl}_{2}$ solution $(\mathrm{Ca} 100 \mathrm{mg} / \mathrm{kg}$ ). In this experiment, the 0-300-s sensitizations among the pre-water, pre-Ca100, and pre-Ca100+Bep groups were not significantly different (Fig. 4A). On the contrary, in the 0-90-s locomotor sensitization, Ca significantly blocked the sensitization induced by EtOH (Fig. 4B) similarly to Fig. 3F. Moreover, bepridil blocked the suppression effect of $\mathrm{Ca}(100 \mathrm{mg} / \mathrm{kg})$ on EtOH-induced sensitization. From the results, we confirmed the effects of pre-administration of $\mathrm{Ca}$ on EtOH-induced sensitization of locomotion. From these results, we speculate that the first $(0-90 \mathrm{~s})$ locomotor peak may be especially influenced by change in plasma $\mathrm{Ca}$ levels induced by $\mathrm{EtOH}$. The pre-administrations of $\mathrm{Ca}$ between 50 
and $100 \mathrm{mg} / \mathrm{kg}$ maintained the baseline $\mathrm{Ca}$ levels even after EtOH administration, which may play a role in the significant reduction of sensitization.

In this experiment, the above results were obtained by usage of Ca100 mg/kg and bepridil $(50 \mathrm{mg} / \mathrm{kg})$, although $\mathrm{Ca}$ channel blockers attenuate ethanol-induced behaviors and neurochemical responses. ${ }^{38,39)}$ We conducted another experiment (water, Ca $75 \mathrm{mg} / \mathrm{kg}$, Ca $75 \mathrm{mg} / \mathrm{kg}$ + bepridil $50 \mathrm{mg} / \mathrm{kg}$; data not shown). In the $\mathrm{Ca} 75 \mathrm{mg} / \mathrm{kg}+$ bepridil group, the sensitization was more suppressed than in the $\mathrm{Ca} 75 \mathrm{mg} / \mathrm{kg}$ group. Therefore, the $\mathrm{Ca}$ pre-dosage for suppression of EtOH sensitization must be within a very strict range.

Effects of Ca after EtOH Administration on EtOH-Induced Sensitization (Locomotor Experiment 4)

We investigated whether $\mathrm{Ca}$ after $\mathrm{EtOH}$ administration showed similar effects on sensitization induced by EtOH as pre-administration of $\mathrm{Ca}$. As shown in Figs. $5 \mathrm{~A}$ and $5 \mathrm{~B}, \mathrm{Ca}$ $1 \mathrm{~h}$ after EtOH $(2 \mathrm{~g} / \mathrm{kg})$ administration significantly promoted both the $0-90 \mathrm{~s}$ and $180-300 \mathrm{~s}$ peaks of the EtOH-induced sensitizations. The results of post-administration of $\mathrm{Ca}(\mathrm{Ca}$ $100 \mathrm{mg} / \mathrm{kg}$, Figs. 5C and 5D) were opposite to those of preCa-administration ( $\mathrm{Ca} 100 \mathrm{mg} / \mathrm{kg}$, Figs. $3 \mathrm{E}$ and $3 \mathrm{~F})$, i.e., the timing of $\mathrm{Ca}$ administration is very important for the sensitization.

We compared the effects of $\mathrm{Ca}$ on changes in plasma $\mathrm{Ca}$ levels between before and after $\mathrm{Ca}$ administration. Increase of plasma Ca levels in the post-Ca100 group $(0.04 \pm 0.03 \mathrm{~mm})$ was not higher than that in the pre-Ca100 group $(0.06 \pm 0.07 \mathrm{~mm}$, Fig. 2B). While it was difficult to explain the differences in plasma $\mathrm{Ca}$ levels between both timings in this experiment, we considered that there were dynamic changes in $\mathrm{Ca}$ signaling, ${ }^{18,19,32,33)}$ which may have optimal Ca levels after EtOH administration. It is well-known that the higher the EtOH doses, the more the sensitization is promoted. ${ }^{6)} \mathrm{EtOH}$ administration dose-dependently arrests the decrease of plasma $\mathrm{Ca} \mathrm{lev-}$ els. $^{21,22,45)}$ Based on these reports and the results of Locomotor experiments 1-3, both EtOH doses and the following changes in plasma $\mathrm{Ca}$ levels by $\mathrm{EtOH}$ affected the progression of sensitization. We measured plasma $\mathrm{Ca}$ levels as total $\mathrm{Ca}$. The active form of $\mathrm{Ca}$ is the free $\mathrm{Ca}$ ion and approximately half of total $\mathrm{Ca}$ is equivalent to the free $\mathrm{Ca}$ ion ${ }^{46)}$; the rest of $\mathrm{Ca}$ is mainly albumin bound-Ca. The free $\mathrm{Ca}$ ion passes through the blood brain barrier ${ }^{47)}$ and the extracellular Ca concentration in the brain depends on plasma Ca levels. ${ }^{48)}$ By sustained stimulation of $\mathrm{EtOH}$, the upregulation of L-type high voltage-gated $\mathrm{Ca}$ channels is induced in the cerebral cortex. ${ }^{49)}$ Moreover, the intracellular $\mathrm{Ca}$ ion is elevated by increased type 1 IP3 receptor via facilitated mobilization of $\mathrm{Ca}$ ions from the intracellular $\mathrm{Ca}$ ion stores to the cytosol by EtOH stimulation. ${ }^{17)}$ Changes in intracellular $\mathrm{Ca}$ dynamics by alcohol stimulation may be observed via two routes during the development of EtOH-induced dependence, i.e., route 1: $\mathrm{Ca}$ influx of exogenous $\mathrm{Ca}$ into the cytosol through $\mathrm{Ca}$ channels in the plasma membrane, ${ }^{49}$ and route 2: Ca release from the stores into the cytosol through Ca release channels mediated by IP3 receptors and ryanodine receptors. ${ }^{16,17)}$ In our results, only pre-administration of $\mathrm{Ca}(\mathrm{Ca}$ dosage $50-100 \mathrm{mg} / \mathrm{kg}$ ) significantly reduced the $0-90$-s peak, but not the 180-300-s peak. The plasma $\mathrm{Ca}$ basal levels directly affected the $\mathrm{Ca}$ channels in plasma membrane (route 1) and the $\mathrm{Ca}$ dosage of pre-administration was important for maintenance of $\mathrm{Ca}$ basal levels (extracel- lular $\mathrm{Ca}$ ). In post-administration of $\mathrm{Ca}$, both " $\mathrm{Ca}$ influx via $\mathrm{Ca}$ channels after stimulation by $\mathrm{EtOH}$ (route 1)" and "Ca release from $\mathrm{Ca}$ ion stores stimulated by both $\mathrm{EtOH}$ and increased $\mathrm{Ca}$ from route 1 (route 2)" might be promoted as a result of increase in intracellular $\mathrm{Ca}$. We speculated that the $0-90$-s peak and the 180-300-s peak were affected by route 1 and route 2 , respectively. We should investigate whether intracellular $\mathrm{Ca}$ levels are changed in relation to plasma $\mathrm{Ca}$ levels after $\mathrm{EtOH}$ and/or oral $\mathrm{Ca}$ administrations.

Inhibition by Dopamine D1 Antagonist of the Development of EtOH-Induced Sensitization (Locomotor Experiment 5)

Intracellular Ca signaling ${ }^{17)}$ and the dopamine D1 receptor contribute to alcohol dependence. ${ }^{29-31)}$ Activation of inositol IP3-induced $\mathrm{Ca}^{2+}$ signaling by dopamine is mediated through D1 dopamine receptors. ${ }^{34)}$ As mentioned above, pre-administration of $\mathrm{Ca}$ which blocked the reduction of $\mathrm{Ca}$ levels by EtOH, especially suppressed the 0-90-s peak (the first locomotor peak) of EtOH-induced sensitization (Figs. 3A-3D, 3F, $3 \mathrm{H}$, and $4 \mathrm{~B})$, but not the second locomotor peak (180-300s). On the contrary, post-administration of $\mathrm{Ca}$ promoted both peaks of EtOH-induced sensitization (Figs. 5A, 5B).

We investigated the role of dopamine D1 receptor in Carelated effective $0-90 \mathrm{~s}$ and/or 180-300-s locomotion. As shown in Fig. 6A, the dopamine D1 antagonist (SCH-23390, $0.01 \mathrm{mg} / \mathrm{kg}$ ) blocked only the first peak $(0-90 \mathrm{~s})$, not the second peak (180-300s). The locomotor sensitization (0-90s) induced by EtOH was blocked in Admin 1-20, although the locomotor activity in the D1-saline group was also blocked by the dose of SCH-23390 $(0.01 \mathrm{mg} / \mathrm{kg})$ (Fig. 6B). On the contrary, SCH-23390 did not block the second peak (180-300s) from Admin 1 to Admin 5 but blocked it from Admin 6 to Admin 20 (Fig. 6C). From these results, both peaks were associated with the dopamine D1 receptor, but its contribution to the progression was changed by repeated administrations of EtOH. Moreover, in the D1-EtOH group the locomotor activities of the second peak were decreased at every weekend interval such as between Admin 5 and Admin 6, Admin 10 and Admin 11, and Admin 15 and Admin 16 (Fig. 6C). The results were contrary to those in the saline-EtOH group. The sensitivities of the dopamine D1 receptor were changed with the sensitization progression by repeated EtOH administrations and the washout period. They may be related to the results that the effects of the pre-administration of $\mathrm{Ca}$ could be observed only after the development of sensitization, but not in the early stage of sensitization from Admin 1 to Admin 5.

Both suppression (Figs. 3F, 3H) and promotion (Figs. 5C, 5D) of locomotor sensitization by $\mathrm{Ca}$ administration were remarkably observed after the progression of sensitization, together with co-occurring changes of sensitivity to dopamine D1 receptor in the 180-300s peak (Fig. 6C). Moreover, locomotor activity was reduced during the withdrawal interval only in the post-Ca100 group (Fig. 5D). Nestler and Aghajanian reported that quantitative and functional changes in proteins affecting dopaminergic signals by repeated cocaine administrations are observed during withdrawal for a few days. ${ }^{50,51)}$ The effects of ethanol-induced sensitization by preand post-Ca administration may be more or less associated with the dopamine D1 receptor arelated changes in sensitivity, although further studies are needed to clarify the relation between extracellular and intracellular Ca levels. 
In humans, drinking volume and drinking duration vary depending on the situation, personal habits, and other factors. Moreover, drinking is sometimes associated with eating, which affects the absorption rate of EtOH. ${ }^{52)}$ Alcohol absorption of spirits was more rapid than that of beer or wine in a study with human participants. ${ }^{53)}$ Therefore, the optimal $\mathrm{Ca}$ dose against plasma $\mathrm{Ca}$ drop by $\mathrm{EtOH}$ is inferred for the drinking. In the relationship between EtOH intake and plasma $\mathrm{Ca}$, Petroianu et al. in a study with human participants reported that there was an inversely related diminution of serum $\mathrm{Ca}$ concentrations with increasing serum alcohol by acute EtOH ingestion. ${ }^{45}$ Moreover, Laitinen et al. reported Ca level changes after EtOH intake in human studies. ${ }^{22,23)}$ For example, they measured serum $\mathrm{Ca}$ concentrations in addition to blood alcohol concentration and blood PTH in humans before and at intervals up to $16 \mathrm{~h}$ after the ingestion of 1.2 to $1.5 \mathrm{~g}$ of $\mathrm{EtOH} / \mathrm{kg}$ over a 3-h period (cross-over study: control was fruit juice). The blood alcohol peak was 4 -h from drinking initiation. After a significant drop of PTH during the 3-h drinking period, the free $\mathrm{Ca}$ ion concentration significantly decreased from $1.18 \pm 0.01$ to $1.15 \pm 0.01 \mathrm{~mm}$ in men, and from $1.20 \pm 0.01$ to $1.15 \pm 0.01 \mathrm{~mm}$ in women after $6-\mathrm{h}$ and the total $\mathrm{Ca}$ (about double concentration to that of the free $\mathrm{Ca}$ ion) presented a similar decrease. ${ }^{23)}$ The decreased amount of total $\mathrm{Ca}$ after 8 -h was $0.14 \mathrm{~mm}$ in that report ${ }^{23)}$ and was similar to the waterEtOH group, in our study as shown in Figs. 1, 2A, and 2B (after EtOH $2 \mathrm{~g} / \mathrm{kg}$, i.p. administration). On the contrary, in the study of serum $\mathrm{Ca}$ concentration (total $\mathrm{Ca}$ ) compared among four $\mathrm{Ca}$ salt supplements (Ca $900 \mathrm{mg} / \mathrm{human}$ participants), the serum peaks were obtained $4-6 \mathrm{~h}$ after $\mathrm{Ca}$ ingestion and the increased amount at the peak (peak-baseline) was about 0.07-0.15 mm. ${ }^{54)}$ Therefore, we consider that plasma Ca changes in humans by EtOH or Ca supplement ingestion are realistically possible, although the Ca doses (Ca $50-150 \mathrm{mg} / \mathrm{kg}$ ) of pre-administration were high in mice compared to human doses.

Moreover, phosphoric acid, a kind of acidic ingredient in soft drinks as a food additive affects $\mathrm{Ca}$ metabolism, such as inducing hypercalciuria. ${ }^{55)}$ We may have to pay attention to both $\mathrm{Ca}$ and food components that cause $\mathrm{Ca}$ excretion.

Based on our results, we should pay attention to high $\mathrm{Ca}$ intake after heavy drinking, because blood alcohol level $1 \mathrm{~h}$ after EtOH $(2 \mathrm{~g} / \mathrm{kg})$ administration remains high. $\left.{ }^{56}\right)$ Laitinen et al. reported that alcohol intake dose-dependently induces hypoparathyroidism, hypercalciuria, and hypermagnesuria. ${ }^{22)}$ Repeated alcohol ingestion led to hypocalcemia. Nutritionally, $\mathrm{Ca}$ supplements should be prescribed for replenishment of $\mathrm{Ca}$ levels after $\mathrm{EtOH}$ consumption. Because $\mathrm{Ca}$ in foods is slowly released through the absorption process after food digestion, plasma $\mathrm{Ca}$ changes may be smaller than those observed with high dose Ca supplements. Ca should be supplied with food, or Ca supplements should be taken before drinking or the day after drinking.

Plasma $\mathrm{Ca}$ levels in patients with alcohol dependence are low compared to those of healthy people, because liver disease is often associated with abnormally low levels of Ca-binding albumin, and these patients may also have impaired vitamin D metabolism. ${ }^{57)}$ Recently, Schuster et al. reported that lowered plasma $\mathrm{Ca}$ concentrations are a risk factor for relapse in patients with high alcohol intake, and especially in patients with increased craving. ${ }^{58)}$
There may be differences in the optimal $\mathrm{Ca}$ doses and timing between healthy people and patients with alcohol dependence.

\section{CONCLUSION}

We investigated the association among oral $\mathrm{Ca}$ ingestion, EtOH-induced locomotor sensitization, and plasma Ca levels. The aim was to elucidate the association between $\mathrm{Ca}$ and EtOH in moderate drinking. Pre-administration of $\mathrm{Ca}$ (50, 75 , and $100 \mathrm{mg} / \mathrm{kg}$ ) significantly reduced the $0-90$-s peak of sensitization of locomotor activity induced by $\mathrm{EtOH}$, but not dose-dependently, as $\mathrm{Ca}(150 \mathrm{mg} / \mathrm{kg})$ did not show the same effect. The effective Ca pre-doses $(50-100 \mathrm{mg} / \mathrm{kg}$ ) corresponded to those for maintaining basal plasma $\mathrm{Ca}$ levels against EtOH-induced decrease of Ca levels. On the contrary, postadministration of $\mathrm{Ca}$ inversely led to significant promotion of sensitization of both locomotor peaks. The effects of $\mathrm{Ca}$ on EtOH-induced sensitization and plasma $\mathrm{Ca}$ levels depended on the dose and the timing of administrations. $\mathrm{Ca}$ ingestion before and after EtOH administration induced diverse effects on EtOH rewarding effects.

Although further research is needed to determine the optimal dosage of $\mathrm{Ca}$ intake to balance losses after drinking in humans, we should take into consideration both the EtOH dosage and the timing of $\mathrm{Ca}$ intake.

Acknowledgments We thank Mr. Yasuhiro Oki, SAPPORO BREWERIES LTD. for advising protocols and Ms. Izumi Nomura, Frontier Laboratories for Value Creation, SAPPORO HOLDINGS LTD., for help with the animal experiments.

Conflict of Interest Chikako Shimizu and Youichi Tsuchiya are employees of SAPPORO HOLDINGS LTD. Yutaka Mitani is a retiree of SAPPORO HOLDINGS LTD. Toshitaka Nabeshima serves as a consultant to SAPPORO HOLDINGS LTD.

\section{REFERENCES}

1) Schmidt W, Popham RE. Heavy alcohol consumption and physical health problems: a review of the epidemiological evidence. Drug Alcohol Depend., 1, 27-50 (1975).

2) World Health Organization. "Global status report on alcohol and health.”: 〈http://apps.who.int/iris/bitstream/10665/112736/ 1/9789240692763_eng.pdf>(2014).

3) Marmot MG, Rose G, Shipley MJ, Thomas BJ. Alcohol and mortality: a U-shaped curve. Lancet, 14, 580-583 (1981).

4) Higuchi S, Matsushita S, Maesato H, Osaki Y. Japan: alcohol today. Addiction, 102, 1849-1862 (2007).

5) Anstey KJ, Mack HA, Cherbuin N. Alcohol consumption as a risk factor for dementia and cognitive decline: meta-analysis of prospective studies. Am. J. Geriatr. Psychiatry, 17, 542-555 (2009).

6) Shimizu C, Oki Y, Mitani Y, Nakamura T, Nabeshima T. Factors affecting ethanol-induced conditioned place preference and locomotor sensitization in mice. Biol. Pharm. Bull., 38, 1935-1945 (2015).

7) Shimizu C, Oki Y, Mitani Y, Tsuchiya Y, Nabeshima T. Moderatedose Regular Lifelong Alcohol intake changes the intestinal flora, protects against aging, and keeps spatial memory in the senescenceaccelerated mouse Prone 8 (SAMP8) model. J. Pharm. Pharm. Sci. 19, 430-447 (2016).

8) Mason BJ. Treatment of alcohol-dependent outpatients with acamprosate: a clinical review. J. Clin. Psychiatry, 62 (Suppl. 20), 42-48 
(2001).

9) Mcgeehan AJ, Olive MF. The anti-relapse compound acamprosate inhibits the development of a conditioned place preference to ethanol and cocaine but not morphine. Br. J. Pharmacol., 138, 9-12 (2003).

10) Williams SH. Medications for treating alcohol dependence. Am. Fam. Physician, 72, 1775-1780 (2005).

11) Pierrefiche O, Daoust M, Naassila M. Biphasic effect of acamprosate on NMDA but not on GABAA receptors in spontaneous rhythmic activity from the isolated neonatal rat respiratory network. Neuropharmacology, 47, 35-45 (2004).

12) Littleton JM. Acamprosate in alcohol dependence: implications of a unique mechanism of action. J. Addict. Med., 3, 115-125 (2007).

13) Spanagel R, Vengeliene V, Jandeleit B, Fischer WN, Grindstaff $K$, Zhang X, Gallop MA, Krstew EV, Lawrence AJ, Kiefer F. Acamprosate produces its anti-relapse effects via calcium. Neuropsychopharmacology, 39, 783-791 (2014).

14) Mann K, Hoffmann S, Pawlak CR. Does acamprosate really produce its anti-relapse effects via calcium? No support from the PREDICT Study in human alcoholics. Neuropsychopharmacology, 41, 659-660 (2016).

15) Spanagel R, Vengeliene V, Kiefer F. Reply to: Does acamprosate really produce its anti-relapse effects via calcium? No support from the PREDICT study in human alcoholics. Neuropsychopharmacology, 41, 661-662 (2016).

16) Katsura M, Shibasaki M, Ohkuma S. Changes in intracellular calcium dynamics observed during the development of alcohol psychological and physical dependence. Nihon Arukoru Yakubutsu Igakkai Zasshi, 42, 59-66 (2007).

17) Kurokawa K, Mizuno K, Ohkuma S. Sensitization of ethanolinduced place preference as a result of up-regulation of type 1 inositol 1,4,5-trisphosphate receptors in mouse nucleus accumbens. $J$. Neurochem., 131, 836-847 (2014).

18) Clapham DE. Calcium signaling. Cell, 131, 1047-1058 (2007).

19) Brini M, Ottolini D, Calì T, Carafoli E. Chapter 4. Calcium in Health and Disease. Sigel A, Helmut RK. Interrelations between Essential Metal Ions and Human Diseases. Metal Ions in Life Sciences. Vol. 13, Springer. pp. 81-137 (2013). DOI: http://dx.doi.org/1 0.1007/978-94-007-7500-8_4.

20) Peng TC, Gitelman HJ. Ethanol-induced hypocalcemia, hypermagnesemia and inhibition of the serum calcium-raising effect of parathyroid hormone in rats. Endocrinology, 94, 608-611 (1974).

21) Nielsen HK, Lundby L, Rasmussen K, Charles P, Hansen C. Alcohol decreases serum osteocalcin in a dose-dependent way in normal subjects. Calcif. Tissue Int., 46, 173-178 (1990).

22) Laitinen K, Tähtelä R, Välimäki M. The dose-dependency of alcohol-induced hypoparathyroidism, hypercalciuria, and hypermagnesuria. Bone Miner., 19, 75-83 (1992).

23) Laitinen K, Lamberg-Allardt C, Tunninen R, Karonen SL, Tähtelä R, Ylikahri R, Välimäki M. Transient hypoparathyroidism during acute alcohol intoxication. N. Engl. J. Med., 324, 721-727 (1991).

24) Steketee JD, Kalivas PW. Drug Wanting: Behavioral sensitization and relapse to drug-seeking behavior. Pharmacol. Rev., 63, 348-365 (2011).

25) Ishikawa K, Nitta A, Mizoguchi H, Mohri A, Murai R, Miyamoto Y, Noda Y, Kitaichi K, Yamada K, Nabeshima T. Effects of single and repeated administration of methamphetamine or morphine on neuroglycan $\mathrm{C}$ gene expression in the rat brain. Int. J. Neuropsychopharmacol., 9, 407-415 (2006).

26) Niwa M, Nitta A, Mizoguchi H, Ito $Y$, Noda $Y$, Nagai T, Nabeshima T. A novel molecule "shati" is involved in methamphetamine-induced hyperlocomotion, sensitization, and conditioned place preference. J. Neurosci., 27, 7604-7615 (2007).

27) Niwa M, Nitta A, Yamada Y, Nakajima A, Saito K, Seishima M, Shen L, Noda Y, Furukawa S, Nabeshima T. An inducer for glial cell line-derived neurotrophic factor and tumor necrosis factor- alpha protects against methamphetamine-induced rewarding effects and sensitization. Biol. Psychiatry, 61, 890-901 (2007).

28) Didone V, Masson S, Quoilin C, Seutin V, Quertemont E. Correlation between ethanol behavioral sensitization and midbrain dopamine neuron reactivity to ethanol. Addict. Biol., 21, 387-396 (2016).

29) Abrahao KP, Quadros IM, Souza-Formigoni ML. Nucleus accumbens dopamine D1 receptors regulate the expression of ethanolinduced behavioural sensitization. Int. J. Neuropsychopharmacol., 14, 175-185 (2011).

30) Camarini R, Marcourakis T, Teodorov E, Yonamine M, Calil HM. Ethanol-induced sensitization depends preferentially on D1 rather than D2 dopamine receptors. Pharmacol. Biochem. Behav., 98, 173-180 (2011).

31) Bahi A, Dreyer JL. Involvement of nucleus accumbens dopamine D1 receptors in ethanol drinking, ethanol-induced conditioned place preference, and ethanol-induced psychomotor sensitization in mice. Psychopharmacology (Berl.), 222, 141-153 (2012).

32) Mizuno K, Kurokawa K, Ohkuma S. Mechanisms of ethanolinduced type I IP3 receptor expression. Nihon Shinkei Seishin Yakurigaku Zasshi, 33, 161-165 (2013).

33) Kurokawa K, Mizuno K, Ohkuma S. Dopamine D1 receptor signaling system regulates ryanodine receptor expression in ethanol physical dependence. Alcohol. Clin. Exp. Res., 37, 771-783 (2013).

34) Swapna I, Bondy B, Morikawa H. Differential dopamine regulation of $\mathrm{Ca}(2+)$ signaling and its timing dependence in the nucleus accumbens. Cell Reports, 15, 563-573 (2016).

35) Broadbent J, Kampmueller KM, Koonse SA. Expression of behavioral sensitization to ethanol by DBA/2J mice: the role of NMDA and non-NMDA glutamate receptors. Psychopharmacology (Berl.), 167, 225-234 (2003).

36) Melón LC, Boehm SL 2nd. Role of genotype in the development of locomotor sensitization to alcohol in adult and adolescent mice: comparison of the DBA/2J and C57BL/6J inbred mouse strains. $A l$ cohol. Clin. Exp. Res., 35, 1351-1360 (2011).

37) Ueda Y, Taira Z. Pharmacokinetic characterization of calcium from three calcium salts (calcium chloride, calcium acetate and calcium ascorbate) in mice. J. Hard Tissue Bio., 21, 291-298 (2012).

38) Broadbent J. The role of L-type calcium channels in the development and expression of behavioral sensitization to ethanol. Neurosci. Lett., 553, 196-200 (2013).

39) Belardetti F. Evolving therapeutic indications for N-type calcium channel blockers: from chronic pain to alcohol abuse. Future Med. Chem., 2, 791-802 (2010).

40) Kurokawa K, Mizuno K, Shibasaki M, Higashioka M, Oka M, Hirouchi M, Ohkuma S. Acamprosate suppresses ethanol-induced place preference in mice with ethanol physical dependence. J. Pharmacol. Sci., 122, 289-298 (2013).

41) Chester JA, Grahame NJ, Li TK, Lumeng L, Froehlich JC. Effects of acamprosate on sensitization to the locomotor-stimulant effects of alcohol in mice selectively bred for high and low alcohol preference. Behav. Pharmacol., 12, 535-543 (2001).

42) Bronner F. Mechanisms of intestinal calcium absorption. J. Cell. Biochem., 88, 387-393 (2003).

43) Trailokya A, Srivastava A, Bhole M, Zalte N. Calcium and Calcium Salts. J. Assoc. Physicians India, 65, 100-103 (2017). http://www. japi.org/february_2017/24_dc_calcium_and_calcium_salts.pdf

44) Sheikh MS, Santa Ana CA, Nicar MJ, Schiller LR, Fordtran JS. Gastrointestinal absorption of calcium from milk and calcium salts. N. Engl. J. Med., 317, 532-536 (1987).

45) Petroianu A, Barquete J, Plentz EG, Bastos C, Maia DJ. Acute effects of alcohol ingestion on the human serum concentrations of calcium and magnesium. J. Int. Med. Res., 19, 410-413 (1991).

46) Tertti R, Harmoinen A, Leskinen Y, Metsärinne KP, Saha H. Comparison of calcium phosphate product values using measurement of plasma total calcium and serum ionized calcium. Hemodial. Int., 11, 411-416 (2007). 
47) Brown RC, Wu L, Hicks K, O'neil RG. Regulation of blood-brain barrier permeability by transient receptor potential type $\mathrm{C}$ and type v calcium-permeable channels. Microcirculation, 15, 359-371 (2008).

48) Goldstein DA, Romoff M, Bogin E, Massry SG. Relationship between the concentrations of calcium and phosphorus in blood and cerebrospinal fluid. J. Clin. Endocrinol. Metab., 49, 58-62 (1979).

49) Katsura M, Ohkuma S. Functional significance of L-type high voltage-gated calcium channels after sustained ethanol exposure. Nihon Arukoru Yakubutsu Igakkai Zasshi, 40, 205-212 (2005).

50) Nestler EJ, Aghajanian GK. Molecular and cellular basis of addiction. Science, 278, 58-63 (1997).

51) Nimitvilai S, Lopez MF, Mulholland PJ, Woodward JJ. Chronic intermittent ethanol exposure enhances the excitability and synaptic plasticity of lateral orbitofrontal cortex neurons and induces a tolerance to the acute inhibitory actions of ethanol. Neuropsychopharmacology, 41, 1112-1127 (2016).

52) Horowitz M, Maddox A, Bochner M, Wishart J, Bratasiuk R, Collins P, Shearman D. Relationships between gastric emptying of solid and caloric liquid meals and alcohol absorption. Am. J. Physiol., 257, G291-G298 (1989).

53) Mitchell MC Jr, Teigen EL, Ramchandani VA. Absorption and peak blood alcohol concentration after drinking beer, wine, or spirits. Alcohol. Clin. Exp. Res., 38, 1200-1204 (2014).

54) Chaturvedi P, Mukherjee R, McCorquodale M, Crowley D, Ashmead S, Guthrie N. "Comparison of Calcium Absorption From Various Calcium-Containing Products In Healthy Human Adults: A Bioavailability Study. Alternative Therapies in Health and Medicine.”: 〈http://www.alternative-therapies.com/resources/posters/pdfs/ poster_albion.pdf).

55) Amato D, Maravilla A, Montoya C, Gaja O, Revilla C, Guerra R, Paniagua R. Acute effects of soft drink intake on calcium and phosphate metabolism in immature and adult rats. Rev. Invest. Clin., 50, 185-189 (1998).

56) Dixon CI, Walker SE, King SL, Stephens DN. Deletion of the gabra2 gene results in hypersensitivity to the acute effects of ethanol but does not alter ethanol self-administration. PLOS ONE, 7 , e47135 (2012).

57) Epstein M. “Alcohol's Impact on Kidney Function. NIAAA.”: 〈https://pubs.niaaa.nih.gov/publications/arh21-1/84.pdf〉.

58) Schuster R, Koopmann A, Grosshans M, Reinhard I, Spanagel R, Kiefer F. Association of plasma calcium concentrations with alcohol craving: New data on potential pathways. Eur. Neuropsychopharmacol., 27, 42-47 (2017). 